\title{
Sensory Aids for the Blind: A Challenging Problem with Lessons for the Future
}

\author{
PATRICK W. NYE AND JAMES C. BLISS, MEMBER, IEEE
}

\author{
Invited Paper
}

\begin{abstract}
The two major objectives of sensory aids for the blind are to permit access to printed matter and to permit safe travel through the environment. The difficulties of designing technological means to achieve these objectives are in many respects unrelated to the concerns of the engineering laboratory. Social, economic, political, and logistic considerations all play a role.

The "blind population" in the United States includes both the totally blind and those with a wide range of visual impairment. This population totals about $\mathbf{4 0 0} 000$ people in which the aged, the multiply handicapped, and those with significant residual vision predominate. Singly handicapped, working-aged people are the initial targets of the current sensory aids. Expension of their range of usefulness to larger fractions of the blind population is expected to come later.

About 800 agencies serve the blind population in the United States, and in 1967 they were responsible for an annual expenditure of $\$ 500$ million. In contrast the sensory-aids research and development budget was less than $\$ 1$ million. Nevertheless, several potentially useful prototype devices have been developed and are about to be evaluated in this country; at least one is of foreign origin. But if these devices are ever to have the opportunity of reeching the blind public, then mechanisms for evaluation, field trials, manufacture, and deployment must be set up.
\end{abstract}

The field of currently active sensory-aids research programs is reviewed. Several programs are concerned with increasing the convenience and accessibility of braille by the application of computer technology. Nevertheless, despite the unquestionable value of these developments, the usefulness of braille is limited by its bulk. its cost, and the transcription time.

To provide direct access to printed documents several devices are being developed that transform optical images from a printed page into auditory or tactile displays requiring motivation and training for effective use. These machines are termed "direct-translation" units and are designed for simplicity and low cost. Other systems utilize print recognition techniques to create a reading machine providing braille or speech as an output. These machines offer potentially faster reading rates and their use promises to be easier to learn than direct-translation machines, but at the penalty of complexity and high cost.

Several mobility aids designed to augment the cane or guide dog have recently been developed. These are also described.

The prospects of achieving direct input to the visual cortex are discussed. It is apparent that the cost of this research is likely to be extremely high in relation to the size of the blind population which might ultimately benefit. Somewhat more easily realizable is a visual substitution system involving stimulation of an area of the skin. Several systems are being developed but all suffer from limitations in image resolution.

Finally, an examination of the organization of research and funding reveals that the U.S. program is small, poorly coordinated, and contains some seemingly unnecessary duplication of effort. Several

Manuscript received June 1, 1970; revised September 2, 1970. This invited paper is one of a series planned on topics of general interest.-The Editor.

P. W. Nye is with the California Institute of Technology, Pasadena, Calif. 91109.

J. C. Bliss is with the Stanford Research Institute and Stanford University, Stanford, Calif. 94305. obvious lessons emerge which, if heeded, could greatly improve the effectiveness of sensory-aids research by providing development, manufacture, evaluation, and deployment services within an integrated program.

\section{INTRODUCTION}

I4 OR more than 150 years braille and the cane have been the two most important aids to the rehabilitation of the blind. The basic needs have not changed and attempts to devise new artificial systems or sensory aids to substitute for sight have usually broken down to the same major objectives symbolized by braille and a cane. The first is to provide a means whereby a blind man can read normal printed matter, and the second is to aid him in traveling and navigating through the environment safely and efficiently. Since the beginning of this century various electronic and mechanical aids have been designed with one or the other of these objectives in view, but success has been extremely limited. The reasons for this slow progress are numerous and stem in large part from technological constraints, limited resources, and an imperfect understanding of the complex processes that underlie the activities these devices are intended to assist. This paper is concerned with a survey of the current state of research on sensory aids for the blind, and will explore the technical, economic, social, and human factors which have influenced and shaped its progress.

For the casual reader to whom the simple title "Sensory Aids for the Blind" may not have aroused great curiosity, a rider has been added. This paper should be of interest to a wider, philosophically inclined readership, because the field it describes exemplifies in microcosm many of the problems that technology will face with greater frequency in the future. The development of mass transportation systems, for example, whether in the air or in urban communities, requires the resolution of numerous social, economic, and logistic problems unrelated to the design office and the engineering laboratory. The point to be made here is that the peculiar difficulties faced in the design of sensory aids for the blind are not also exclusively technical. The problems lie in the creation of a device capable of achieving an intimate interface between the blind user, his environment, and his society. Thus it is important that we understand the characteristics of the blind population and the attitudes of society towards it, for these factors have had, and will continue to have, an important influence on the 
directions taken by various research efforts. With this in mind it is appropriate to begin by reviewing some of the major characteristics of the blind population in the United States.

\section{Characteristics OF THE BLIND Population}

The term blindness embraces a spectrum of visual defificiency, ranging from a level at which it is possible to read with special optical aids to total blindness. The definition of economic blindness ${ }^{1}$ used in registers of the blind varies slightly from state to state, but the most commonly adopted rubric both here and abroad is a visual acuity of less than $20 / 200^{2}$ in the better eye using the best optical correction, or visual acuity of more than $20 / 200$ if the widest diameter of the field of vision subtends no greater than 20 degrees. Thus the use of the collective noun "the blind" should be understood to imply the totally blind and the severely visually impaired.

At the present time there are no accurate figures for the total number of blind people in the United States, but there are in existence three principal estimates [1] as given in Table I. Of these estimates, the highest is more than three times the lowest. Wide variations exist because the different agencies use different definitions of blindness, different test methods, and different sampling procedures [5]. Schon [1] suggests that this state of the data may be the norm in social and medical fields rather than the exception. If the various subpopulations of the blind were known only to an accuracy of plus or minus 15 percent, he indicates that we could improve the rationality of our allocation of national resources on research, both in preventive medicine and in rehabilitation. In the context of planning the development of sensory aids, the lack of accurate data on the number of potential users and their present habits and capabilities is also to be regretted [6] although some insight on this subject may be gained from a unique study carried out by the Government Social Survey in England [7].

Several of those who have worked with the economically blind have observed that the same objectively measured visual defect incapacitates people to a different degree. In one respect this may be attributed to a deficiency in the Snellen metric which gauges primarily distance vision, but more profound than this is the fact that measurements of visual acuity give very little indication of the functional efficiency of a blind person. Several authors have cited the need to develop measures of visual, sensory, motor, psychological, and motivational factors [8]-[10] among the blind, and a considerable amount of research into these questions is still required. In addition the precise effects of blindness on personality, abstract functioning, and concept development are important questions which are receiving some attention, primarily in children [11], [12]. The answers can have an

\footnotetext{
${ }^{1}$ The term legal blindness is sometimes used loosely in this context. However, the term legally blind applies only to a person qualified for public benefits under a definition embodied in law [5].

${ }^{2}$ An acuity expressed as $20 / 200$ indicates that the subject can see, at a distance of 20 feet, letters on a Snellen chart which a person with normal sight can see at a distance of 200 feet.
}

TABLE I

\begin{tabular}{lcc}
\hline \hline Source & $\begin{array}{c}\text { Rate per 1000 } \\
\text { Population }\end{array}$ & $\begin{array}{c}\text { Total } \\
\text { United States }\end{array}$ \\
\hline MRA projection to total (1966) & 1.5 & $290000[2]$ \\
NSPB fact book (1965) & 2.1 & $416000[3]$ \\
National health survey (1968) & 5.6 & $1090000[4]$. \\
\hline
\end{tabular}

important influence on the development of rehabilitation techniques and sensory aids that a blind or visually impaired person will readily accept.

The characteristics of the "visible" blind population, i.e., those that are known to the organizations and agencies concerned with blindness, have changed significantly since 1900. From 1900 to 1930 the blind were identified primarily as children and adults of working age, and the dominant causes of blindness were war, industrial accidents, and disease. The blind were assumed to have only the single handicap of blindness. Today, the population of the severely visually impaired in the United States is heavily weighted toward the aged blind, the multiply handicapped, especially among children and the poor ethnic minorities, especially the low-skilled, and those with significant residual vision. The estimates vary from 40 percent (MRA) to 65 percent (NHS) as to the proportion of blind persons over 65 . The dominant causes of blindness among the old are degeneration, diabetes, and other multiple etiologies characteristic of increasing age. Among children the dominant causes are genetic and prenatal influences [13] which tend to be associated with other disabilities in addition to blindness. But it is apparent that to a very great degree the problems of blindness are synonymous with the problems of aging [14].

This shift in the makeup of the "visible" blind population has tended to greatly complicate the task of developing sensory aids, particularly if it is assumed that these aids must serve a major body of the blind population. In reaching more pragmatic intermediate goals, it is likely that the aged and other large portions of the economically blind community may be excluded for a variety of reasons.

For example, at the outset it is apparent that the major potential beneficiaries of the first widely available reading machines and mobility aids will probably be under 65 years of age with a single impairment of blindness. Moreover, since these people do not form a homogeneous group (a wide range of ages, capabilities, and interests are represented), it is extremely unlikely that a reading machine or mobility aid will be of universal utility, or even desired by a large proportion. This is indicated by the fact that less than two percent of the population use guide dogs and only about ten percent can read braille. ${ }^{3}$ The reasons for these low figures reflect differences in personality, education, training,

\footnotetext{
${ }^{3}$ The cane and Talking Book are more widely used than the guide dog or braille. Techniques for producing tape-recorded speech are coming into use making possible a listening rate up to twice the recorded rate with no increase in pitch. More information on this technique can be obtained from Dr. E. Foulke, Center for Rate-Controlled Recording, University of Louisville, Louisville, Ky.
} 
and sensory motor abilities, as well as a balance between the motivation to read or be mobile and the effort and responsibilities which this entails. Therefore the acceptance of existing aids is probably influenced as much by deliberate choice as by any restrictions in their availability and utility. Furthermore, under these circumstances one should not expect that new technological aids will be treated differently unless they are of significant help in gaining wider vocational opportunities or in increasing human functioning. If this goal can be achieved, statistics indicate that there is a likelihood that sensory aids would be utilized by a substantial number of able-bodied blind people amounting to possibly ten percent of the total blind population. It is essentially to these people that reference is being made in this paper. This group is likely to be most suited and motivated to use technological innovations, especially those requiring considerable perceptual and motor skills, a requirement which is a characteristic of most sensory aids currently under development.

\section{The Attitudes of Society Towards Blindness}

Blindness has, throughout history, been regarded as one of the most disabling afflictions known to man. Public concern for the welfare of the blind began to seriously develop about 200 years ago, and during the intervening period there has been a considerable growth of medical knowledge of the causes and characterization of blindness. Through effort in public education and improved medical practice a great deal of blindness can now be avoided. But once visual defects are contracted, very few are completely cured. In contrast to what was the prevailing attitude of the past, blindness today is not feared as much as many other diseases. In a nationwide survey cited by Josephson [15] half of those interviewed rated cancer the most terrible of all diseases, while less than one-fifth held the same view about blindness. Thus in the last $\mathbf{4 0}$ years the fear of blindness has decreased rather sharply, and there is evidence that private support through gifts to agencies for the blind has undergone a similar decline relative to the money received by organizations seeking funds to aid people disabled by the other diseases. However, this trend has been countered by the social security legislation which began in the early 1930's and more recently, in the case of the elderly, by Medicaid and Medicare. Nevertheless, society by no means fully compensates the economic disadvantage suffered by the blind. In a recent survey [4] it was shown that about 56 percent of visually impaired people in the United States received an annual family income of less than $\$ 4000$. This figure is influenced by the predominant presence of the elderly population indicated in Fig. 1. Nevertheless, of those under 65 years of age, 70 percent receive less than $\$ 7000$ per annum. While not all of society's activities are controlled by the pressures of the market place it can be fairly stated that the blind population does not directly constitute an attractive potential market, and this fact has discouraged both large and small businesses from investing money, for profit motives, in the design and manufacture of aids for the blind.

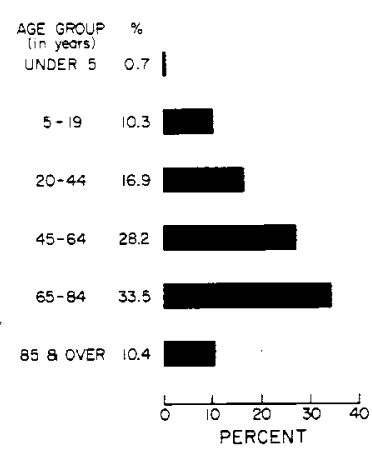

Fig. 1. The distribution of total cases of registered blindness by age group, from statistics from [2].

A national systems study [1] embracing all economic aspects of the delivery of welfare and other services to the blind and visually handicapped estimated that a halfbillion dollars annually is provided by private, federal, and state agencies in welfare support and other services to the blind. Scott [16] has shown that these resources are funneled through approximately 800 agencies for the blind. He makes a strong case that this incredible fragmentation has tended to insulate these agencies from such major changes as shifts in the makeup of the blind population, so that only about 20 percent of the total blind population are actually being served by these agencies today.

However, specifically in the area of sensory-aids research and development, the government agencies, which are easily the primary source of research funds, committed in the year 1967 a little less than \$1 million [17] (0.2 percent of gross). Thus the greater portion of the money devoted to the blind is directed towards providing support (averaging $\$ 1700$ per year per person) and this is further supplemented by money contributed by relatives and friends of those affected. It has been argued that a greater investment in the development of sensory aids would enable blind people of working age to command higher salaries and in some measure offset this investment by making a significant return to the treasury in taxable income [18], [19].

With a wide spectrum of conflicting demands on its resources, the question of the degree to which society should be prepared to provide aid to the blind or any other group with some physical impairment is particularly difficult to determine at the present time. Even so, it is a fact that we are spending large sums of money on prosthetic devices designed to relieve the afflictions of those affected by heart disease, and other disabilities. Logically the assessment of priorities on the expenditure of the limited research funds is a public health decision which one should attempt to base on a scientific evaluation of the chances of success and the human values involved [20], but it is difficult to find convincing evidence that this is in fact being done. Calculated on a per-potential-patient basis, there is an inexplicably large discrepancy to be found between the amount spent on blindness rehabilitation research ( $\$ 1.25$ per patient) and the amounts spent on similar functions carried out within a number of the more widely publicized public health programs, particularly, for example, on the treatment 
of victims of cancer ( $\$ 220.00$ per patient) and heart disease (\$76.00 per patient) [19]. It is probable that the relative priorities implied by these figures reflect closely the likelihood that any particular member of society may fall victim to the particular disease and thus represents the emotional response that this prospect evokes. However, the cost limitations that a policy based on these criteria imposes severely circumscribes the range of aids to the blind which can be considered practicable, their implementation, their technical proficiency, and their deployment.

\section{The ObJectives and Problems of Sensory- AID DEVELOPMENT}

The ideal objective of all visual or sensory aids must be to contribute significantly in assisting the blind user to approach a position of functional equality with sighted people. No single general purpose aid can be expected to serve the entire range of requirements. Different aids are likely to provide more efficient service in different roles. All sensory aids can be seen as consisting of three basic elements: the environmental sensor, the information processor, and the display to interface with the user. In principle, given adequate ambient illumination, a television camera can gather all the necessary optical information. It is at this point that difficult technical problems appear because this information must now be processed and displayed in such a way that the human can readily use it. Of the senses available to most blind people the tactile and auditory present the best prospects, but their combined capacity, measured in terms of the number of nerve fibers, is barely $1 / 20$ th that of the absent visual channel. To have any hope of satisfactorily utilizing substitute sensory channels we must determine the way in which optical signals must be transformed so as to match the channels efficiently. Successful implementation of this matching depends upon a detailed knowledge of the processes of auditory and tactile communication both at the peripheral level and within the brain itself. However, this knowledge is not at present available, although fundamental research of a psychophysiological nature may eventually reveal significant approaches. Thus the guidance this knowledge now provides on the potentialities and characteristics of auditory and tactile communication is restricted to somewhat broad generalizations.

For example, in the auditory domain numerous experiments have indicated that complex nonspeech sounds having many perceived dimensions such as pitch, loudness, repetition rate, etc. can convey more information more rapidly than unidimensional signals. Also certain kinds of signal redundancy can reduce the risk of error in the presence of noise. Some studies have indicated that the perceptual processes operate on discrete bundles of information that are segmented within a short-term memory, although the conditions governing this segmentation are not understood. It is perhaps significant, however, that these segmentation processes are evident in the structure of natural languages and the production of speech. Nevertheless, speech can be understood at rates exceeding 200 words per minute (wpm) indicating that the auditory channel is capable of processing complex signals at high rates, while all attempts to match these rates with nonspeech audio signals have failed. The explanation of this failure is emerging through evidence suggesting that there are coding and decoding operations, carried out in a part of the brain not used by other sensory inputs, unique to the speech process. Thus there are inherent factors which favor speech discriminations and make them faster than those carried out on nonspeech sounds. The designer of a reading aid must face the dilemma of whether he should seek simple low-cost solutions which generate outputs whose efficiency may not be high, or whether, with the cost of complexity, he should build equipment capable of generating speech and exploit well-established perceptual processes.

The tactile modality, on the other hand, offers the immediate advantage that simple point-by-point transformations of spatially related objects or patterns (for example, printed characters) can be made, thus providing an output which is highly compatible with the sense of touch. Various studies of the tactile sense have revealed basic properties, many of which are shared by the visual system. For example, the results from several psychophysical experiments have shown that both the visual and tactile reading rates (i.e., with highly trained tactile readers) are roughly proportional to the number of letters (including fractional parts) contained within the field of view [21]. However, too little is yet known to permit confident prediction of where the maximum possible rates of communication lie and what types of display devices permit optimum levels of performance with the least stress. In the face of this general lack of information, attempts to produce an adequate interface between a visual aid and the user's tactile or auditory senses must depend heavily upon trial and error methods not all of which can be applied within the laboratory. The consequence of this dependence cannot be stressed too strongly because it creates an important shift of emphasis in the strategy of research and development. It means that extensive training and evaluation procedures must be evoked to provide empirical data to guide further research and hence training and evaluation become a more intimate and important part of the research and development process than is customarily implied in the term R and D.

\section{Past History of SENSORY-AID DeVelopment}

The development of sensory aids for the blind has been well documented, and many previous surveys have been written [22]-[27]. The reader who studies these early endeavors may well be surprised at the ingenuity and diversity of past technological proposals and efforts dating from the beginning of this century.

For example, in 1912, Fournier d'Albe invented a device called the Exploring Optophone which was intended as a general aid to the blind in finding their way about by detecting the light from doors, windows, and light objects. In operation, the device allowed ambient light to fall on a selenium cell connected in a Wheatstone bridge. The current to the bridge was interrupted periodically to generate a buzz tone in a pair of earphones (related to bridge imbalance). 
This system was later modified to give information about the black-on-white characters constituting a printed page [28]. For this application a vertical column of illuminated spots of light was moved horizontally across the printed material. The light in each spot was chopped at a different rate and the total light reflected from the page and a portion of the light from the incident beam was sensed by two selenium cells connected in a bridge. Thus, the output signal from the selenium bridge was composed of the out-of-balance modulation frequencies caused by the reduction in reflected light produced when the illuminated spots fell on a printed character. The modulation frequencies were arranged so that tones of low pitch represented low regions of a letter and high-pitched tones the upper regions. The user was expected to recognize the printed letters by listening for the chords and tones corresponding to the inked portions of each character as it was scanned by the narrow slit field of view.

The Optophone represents one of the earliest direct approaches to the problems of reading and mobility and, furthermore, was successful to a degree. By 1923 Miss Mary Jameson, one of the original students of Optophone reading, gave a public demonstration, and speeds of $60 \mathrm{wpm}$ were reported. However, later evaluations of the device indicated that reading rates as high as those achieved by Miss Jameson could be attained by only an extremely small number of blind people, and Optophone development consequently languished. More recently there has been a revival of interest in the broad principles of the Optophone, and new designs exemplified by the Battelle reader [29] and Mauch Visotoner [30] have emerged. Modern technology has not, however, led to a significant improvement in user performance, but the rationale for pursuing further development has been that if a device of this kind can be of help to at least some people for some tasks, and if it is reasonably inexpensive, then it should be made available.

During the last 50 years many technical devices such as the radio, telephone, and more recently the tape recorder have played an important part in the lives of active blind people, but it is significant that these and most other devices in use by blind people today owes much of their present availability to their usefulness to the population as a whole. However, the blind community has stimulated generally useful developments. For example, work on the development of the fountain pen and the long-playing microgroove phonograph record [31] have been attributed to organizations for the blind, but their ultimate success again rests on their appeal to society at large. Nevertheless, while some of these devices have been found to be very useful, there is still little available to a blind person to significantly aid him with his two major problems, direct access to printed material and mobility.

The initial stimulus for current research efforts on reading and mobility aids can be traced back to the end of World War II when studies were instituted by the Committee on Sensory Devices of the Office of Scientific Research and Development and later transferred to the National Academy of Sciences. Since that time the number of investigators in the field has grown steadily. We do not propose to dwell further on this period because it has been thoroughly described in the surveys already cited. This paper will concentrate on an examination of current technical programs, research goals, and future needs in the sensory-aids field.

\section{Vocational AiDs}

Vocational aids range from portable braille writers, of which 50000 were manufactured by the Perkins School for the Blind between 1951 and 1969 , to machine shop tools fitted with braille scales and devices to provide tactile and auditory readout from a number of frequently used electronic instruments, such as the voltmeter. The design of such aids has always been an active field of exploration for the individual inventor in this country. Nevertheless, the range of different devices that have been made available to the blind public has been painfully small. Frequently devices have been imported from Europe where development and manufacturing programs have been under way on a small scale for many years.

If there were no other reason than the fact that the blind population does not represent an attractive potential market, it would appear inexplicable why so many technologically straightforward devices, which nevertheless have utility for the blind or visually impaired, fail to reach the production stage. An excellent case in point is the electronic image intensifier described by Genensky [32] and others [33]-[35]. Consisting basically of a television camera and monitor, the system provides an enlarged high-contrast image of the printed page at a comfortable height and optimum eye-screen distance for the partially sighted user. Genesky estimates that approximately 60 percent of the economically blind population have sufficient residual vision to read successfully with such a system if the contrast of the printed or handwritten material can be raised sufficiently. In a sample of 50 economically blind people he found 80 percent were able to read and write with the device in a few minutes. Some of these people had previously been unable to write unaided with a pen or pencil. In some cases additional image enlargement may be desirable, although its benefits are frequently offset by a restricted field of view. There has been no technical reason why an image intensifier could not have been developed for use by the partially sighted at any time during the ten years that have elapsed since it was originally proposed in 1959 [34]. A lowcost system developed by the Massachusetts Commission for the Blind, M.I.T., and the Boston University Low Vision Clinic is now being used by some ten clients on a regular basis [35]. Yet despite the fact that a very modest amount of work is required to design suitable controls, this device, which could be of service to a considerable proportion of the blind population, is still not widely available. In one respect this example typifies the neglect of an opportunity in rehabilitation, in another it illustrates the neglect of the partially sighted segment of the economically blind community which does not always obtain the recognition that its size deserves.

An encouraging outgrowth of the past decade has been 
the emergence of new organizations set up by blind people and catering to the need to produce useful devices both here [36], [37] and in Canada [38]. Yet another recent development has been the training program for blind computer programmers sponsored by the Association for Computing Machinery [39] which has stimulated the design of various aids needed by its students. Several computer manufacturers have produced modified line printers that can provide output information in the form of embossed Braille characters. Other devices have been designed for blind students by the engineering faculty at M.I.T. [40], [41]. These studies of the potentiality of computer programming as a career for blind people represent a significant step in the expansion of their vocational opportunities. Nevertheless, as rapidly as new jobs are born so also can new technical innovations soon destroy them. While the expanding development of time-sharing computer systems and the practice of programming machines by means of interactive visual cathode ray tubes (CRT), displays, and teletype writers promises to increase the sighted programmer's productivity, it may eventually threaten the livelihood of the blind programmer in those installations not prepared to bear the cost of special equipment and software.

Surveying the field of vocational aids as a whole, however, it is strikingly apparent that most of the impetus for new vocational aids still comes from active members of the blind community who wish to overcome obstacles they meet in the course of attempting some new task. There is still little organized effort under way on the part of the sighted community to seek out potential employment for blind people and to design the necessary means to enable them to work effectively. While greater use could be made of devices and techniques available today, the number of potential opportunities these devices make possible appears to be limited. It is apparent that devices that can make a significant difference in these opportunities are likely to require appreciable advances in technology and science. Because this required knowledge is likely to be of a specialized nature, it becomes correspondingly less probable that revolutionary aids will evolve naturally within our society and have practical value for us all. Therefore, special efforts at establishing an organized framework within which devices can be designed, developed, evaluated, and subsequently marketed must be made.

\section{CURRent Research: Braille DeVelopment}

The braille code has been in use for about 150 years, although it has not always appeared in its present form. One popular misconception firmly entrenched in the folklore of blindness is the idea that all blind people learn to read braille. In fact braille reading may occupy barely 10 percent of the economically blind community, and the remainder either have sufficient vision to read some print, have no interest in reading the kind of material available, or fall in the mid-region in which knowledge of braille is still regarded as unnecessary and the thought of learning braille repulsive because it symbolizes submission to blindness. A good braille reader can read at speeds of $200 \mathrm{wpm}$; a fact which illustrates that information can be transmitted through the sense of touch at high rates.

Among the better known services is the Library of Congress Books for the Blind program which subsidizes braille and recorded Talking Books produced by the American Foundation for the Blind and the American Printing House for the Blind. In addition, volunteer groups throughout the country provide braille transcription services through regional centers manned by an estimated 2300 braillists (almost all part-time volunteers) representing a considerable manpower resource. The number of braille readers in the United States is estimated to be between 30000 and 40000 persons which would indicate that there are about 15 readers for every braillist. But despite this apparently favorable ratio between the translators and their readership, the delivery of braille is not as fast and flexible as the blind community needs if they are to compete with the sighted. The braille code is complex and a braille transcriber can encode braille at an average rate of only $12 \mathrm{wpm} \mathrm{[42].} \mathrm{In}$ addition, a moderate-sized novel with about 400 pages becomes, in braille, four books, each the size of a volume of the Encyclopaedia Brittanica. The sheer bulk of a braille transcription, the time it takes to produce, and the cost, severely limit the total number of books that are available in libraries for the blind. Less formal materials (notes, exams, journals, etc.) of which frequently braille copies are needed virtually immediately, suffer from intolerable delays or are found to be totally unavailable.

Several attempts have been made to solve the problem of size by storing braille text on punched paper tape or magnetic tape instead of the stout paper on which braille is usually embossed. The tape is then read by feeding it into a device that senses the information and displays the text a line at a time by means of an array of electromechanically energized pins [43], [44]. Another approach to this problem is to use reformable moving plastic belts upon which braille can be written, read, and then erased [45].

The matter of increasing production speed has been attacked by employing automated methods based on computer translation of English to braille [44], [46], [47], but the expected rewards have not yet been fully reaped for a number of reasons. First of these is that the input material, usually inkprint, must be converted to computer tapes or cards by hand keypunching, and this is time consuming, although faster than braille transcription. New optical character recognition systems may eventually help solve this problem. However, the input bottleneck can be circumvented now to some degree by utilizing the compositor's type-setting tapes prepared for the production of the inkprint edition of a book. In a demonstration project conducted in 1968, a braille edition of the novel The East Indiaman [48] was prepared using the M.I.T. Dotsys I system with embossing by the American Printing House for the Blind and appeared only a few weeks after the printed copy.

Secondly, the computer transcription algorithms do not produce perfect braille code but must be augmented by "look-up" tables for exception cases. Although the error 
rate is low, the code must nevertheless be proofread because, lacking much of the redundancy of printed text, braille errors can cause greater difficulties than would be the case were the text reproduced in letter by letter form. The difficulties with the computer algorithm lie in the fact that correct Grade II contracted braille transcription requires the application of a complex hierarchy of rules, some of which defy simple operational definition. Grade II braille utilizes a number of single symbols which represent commonly occurring groups of letters such as, for example, BE, CON, and DIs which, incidentally, can be used only as syllables and at the beginning of a word. Some of these rules depend on an analysis of the semantics of the words, or context in which they appear, and pose problems similar to those barring the way to the accurate machine translation of natural languages [49].

Despite these difficulties the now well-tuned program (running on an IBM 709) at the American Printing House for the Blind has produced since 1964 over 1000 books by computer translation [50]. The cost of computer braille is in the "same range" as that produced manually and the computer is used "regularly in production" compensating for the "acute shortage of trained transcribers," a national problem.

More recently a machine transferable braille program Dotsys II (using COBOL coding) [51] has been developed by M.I.T.-Mitre Corp. This should make computer translation into braille accessible to anyone with free or rental access to many different computers of different manufacture and configuration. The first production use of this program will be in the Atlanta Public School System where an IBM 360/50 will be employed.

The third need is for output devices to emboss the tactile braille symbols. Conversion kits are available which produce excellent braille on commercial chain printers. In addition, for the more tolerant braille readers (especially blind programmers), jury-rigs, using the period sign and an elastic backing to the print hammer, produce readable braille. The M.I.T. Sensory Aids Center is producing in limited quantities a remote console Braillemboss [44] which produces paper braille at 16 characters per second, thereby providing blind users remote and time-shared access to braille translation of computer input. This system is now operational at the Perkins School for the Blind in Watertown, Mass., (on both the M.I.T. 7094 using the Dotsys program and on the GE time-shared system) and at NASAElectronic Research Center in Cambridge on a PDP-10. By the end of 1970, 20 of these units will be operational in the United States and in Europe. Scheduled applications include time-shared, remote access installations in public schools and educational institutions for the blind, vocational applications for blind programmers and researchers in university computation centers, government and industrial research facilities, and for blind radio newscasters who will receive braille direct from the teletypewriter newswire. Several of the applications in this country and Europe will employ the Braillemboss hardware and Dotsys II software to produce volume braille in stand-alone systems, or by use of rental computer for translation and magnetic tape drive for off-line production of braille.

However successful, computer braille cannot begin to meet all of the needs of the blind for access to printed material. Many books and journals, especially those not widely read, will not be produced in braille; more important, great volumes of special and informal inkprint, e.g., correspondence, notes, preprints, briefs, etc., will appear in braille only under the most extraordinary conditions. Beyond this matter of braille supply, there is the inescapable fact that many of the blind never learn to read braille at all, or never read well enough to use the medium effectively. Thus efforts have been made to provide a device or reading machine which would enable a blind person to obtain direct access to the printed page.

Several different approaches to the solution of this problem and its companion the mobility problem have been made, but it is not easy to classify these various sensory aids in a simple manner by input (whether by touch, ear, or direct cortical implantation), or by degree of complexity and possible cost. Nevertheless in Fig. 2 we have attempted to provide an at-a-glance review of the current areas of activity.

\section{Current Research: Direct-Translation READING AIDS}

The reading speeds achieved by a good braille reader testify to the effectiveness of the tactile sense as an input channel. As has been pointed out earlier, braille reading speeds are enhanced by the use of simplified six point symbols and contractions which together eliminate much of the redundancy contained in printed characters and printed text. However, the automatic translation from print into braille requires a complex processing system, including a multifont character recognition capability, which cannot yet be made portable at low cost. Technically simpler and potentially cheaper devices producing facsimile displays of optical characters, either tactually or auditorily, can be built in compact form. Several such direct-translation reading aids are currently being developed and tested. For example, a device called the Optacon, [52], [53] shown in Fig. 3, has been developed at Stanford University and Stanford Research Institute. This device is in everyday use by a few blind people as a pilot test. These people have achieved reading rates from 20 to 70 wpm with the Optacon and all feel that this is very useful to them, especially for such documents as correspondence, magazines, some books, the dictionary, educational materials, and typing. One of these readers uses the Optacon in his job for reading computer listings and punched cards.

The Optacon translates an area on the printed page about the size of a letterspace into a facsimile tactile image. This tactile image is produced by a 24 -by- 6 array of small rods driven by piezoelectric reeds and the entire array fits on a single finger. The reader senses the tactile image with a fingertip of one hand while he moves a small optical pickup probe across the line of print with the other hand. This probe contains a monolithic silicon integrated array of 144 


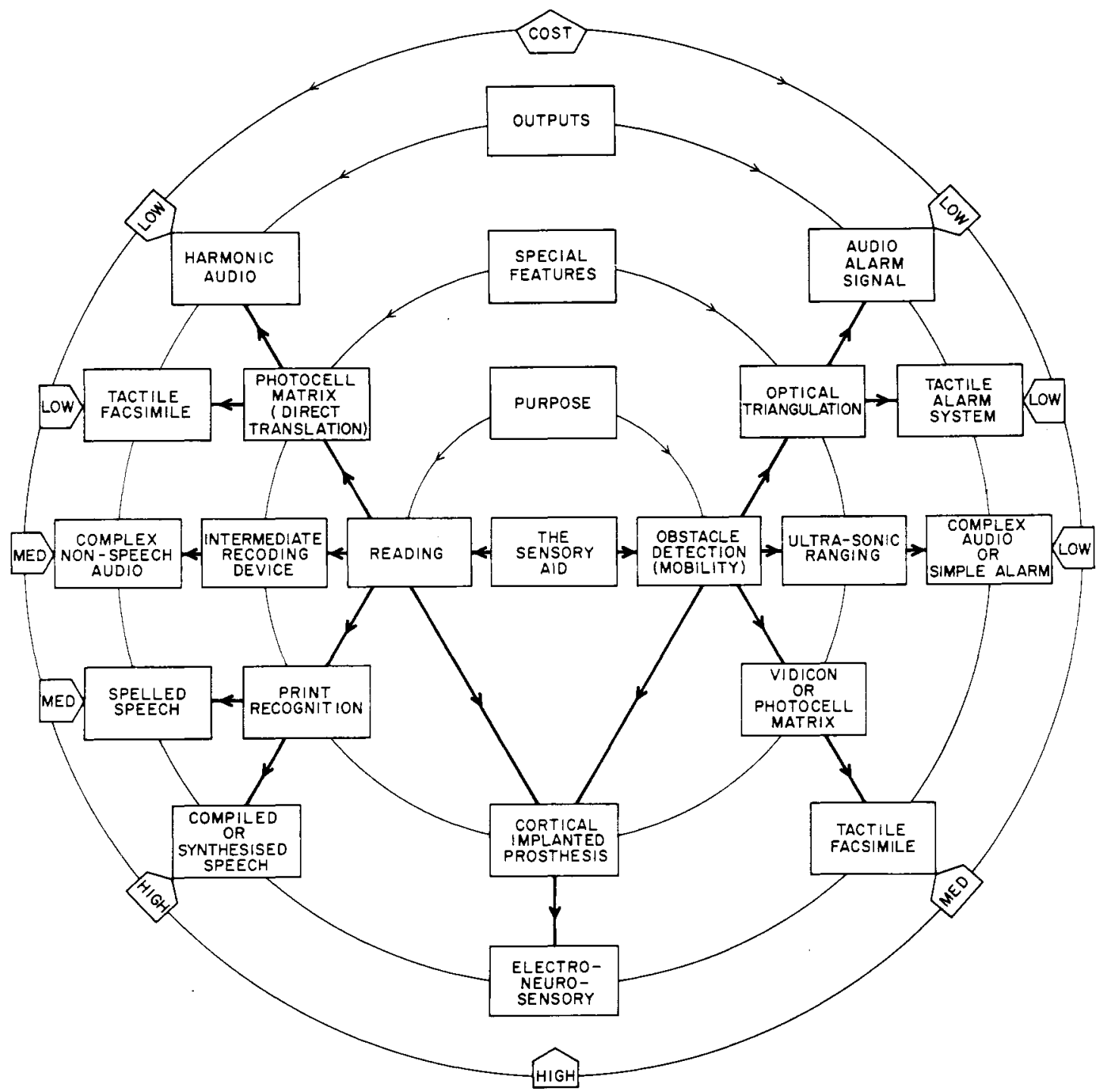

Fig. 2. A classification of the various types of sensory aids, their purpose, special features, outputs, and approximate cost.

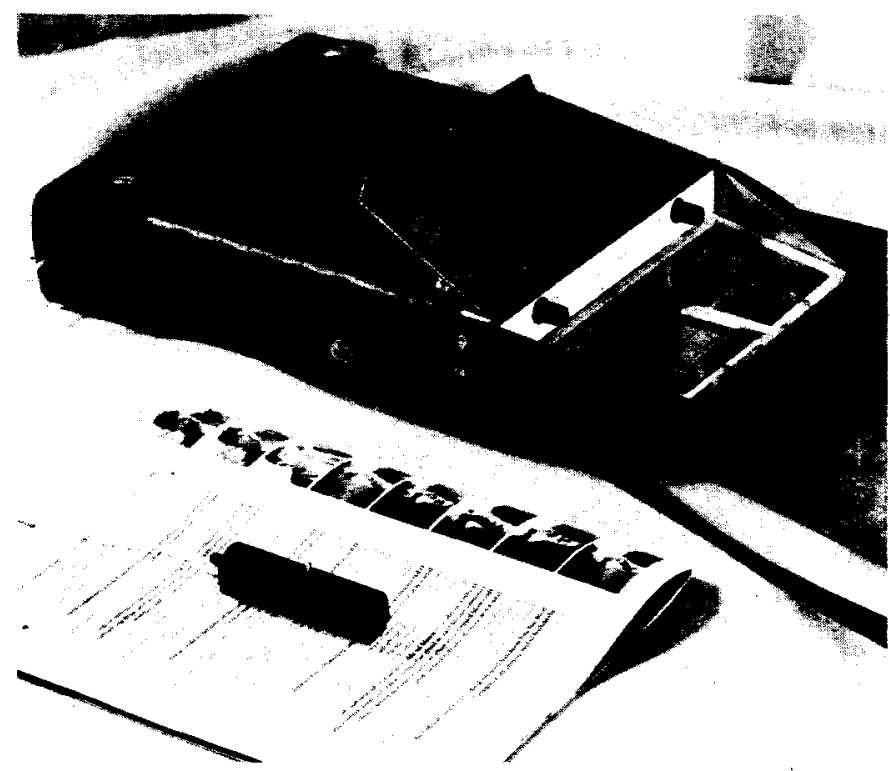

Fig. 3. The Optacon: a direct-translation reading aid which presents on a 24 by 6 matrix of stimulators, a tactile facsimile image of printed characters scanned by the optical probe. phototransistors [54] and an optical system capable of changing magnification over a 2.5 to 1 range. The complete Optacon as a unit weighs about $8 \mathrm{lbs}$.

Since the process of learning to read with the Optacon requires a significant amount of training and practice, some consideration has been given to the development of equipment to assist the student. An electronic system has been developed that enables signals recorded by an ordinary audio tape recorder to produce moving alphabetic images on an Optacon. This unit is used to teach tactile image perception without hand tracking and to build up reading speed by forced pacing.

By attaching an auxiliary lens onto the Optacon probe and making some minor modification to the electronics, the unit can also be used for exploring the environment [55], [56]. This additional application is currently under study.

Other direct-translation reading aids are independently being developed by Mauch Labs., for example, the Visotoner and the Visotactor, (see Fig. 4) [30]. These two devices have a similar input system and are similarly packaged, the 


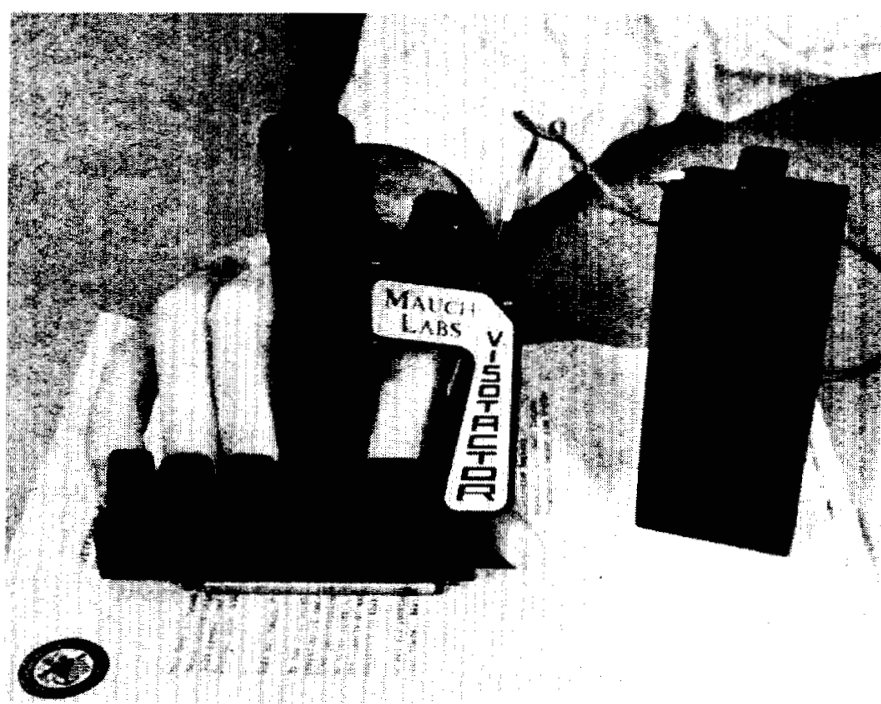

Fig. 4. The Visotactor: a direct-translation reading aid which utilizes 8 stimulators ( 2 stimulators per finger tip) that are built into the optical probe.

major difference being that the Visotoner has an auditory output composed of sequences of chords, similar to that produced by the Optophone, and the Visotactor has a tactile output. A combined total of about 40 of these units have been built and roughly 15 are in use by blind people. Reading rates up to 40 wpm have been reported with the Visotoner but only about $15 \mathrm{wpm}$ has been achieved with the Visotactor.

The Visotoner and Visotactor image a narrow slit from the letter-space onto a one dimensional array of 8 (in the Visotactor) or 9 (in the Visotoner) CdSe photocells. The photocell signals activate corresponding oscillators whose outputs are summed to produce the chords played through an earphone. As in the original Optophone [28] the tones produced by the oscillators are arranged so that the bottom photocell corresponds to the lowest frequency tone and the highest photocell corresponds to the highest frequency tone.

In the Visotactor the eight photocell signals are mapped into eight tactile stimulators, two on each of four fingertips. The stimulators are contained in the unit that also contains the optical pickup system so that the tactile sensing is done with the hand that scans the print.

The resolution and field of view of the Visotoner and the Visotactor are severely limited, and both devices require precise manual tracking which is provided by a third component termed the Colineator.

Mauch Labs is also developing a device called the Digitactor that "will be a multicolumn direct-translation tactile reading aid which fits and stimulates the underside of one finger; probably the index finger of the hand which scans the page."

Besides the direct one-to-one transformations between input sensors and output stimuli being employed in the reading aids just described, some forms of rudimentary image processing are being tried for the purpose of making less training necessary and faster reading rates possible. The Lexiphone, [57], [58] under development by Beddoes

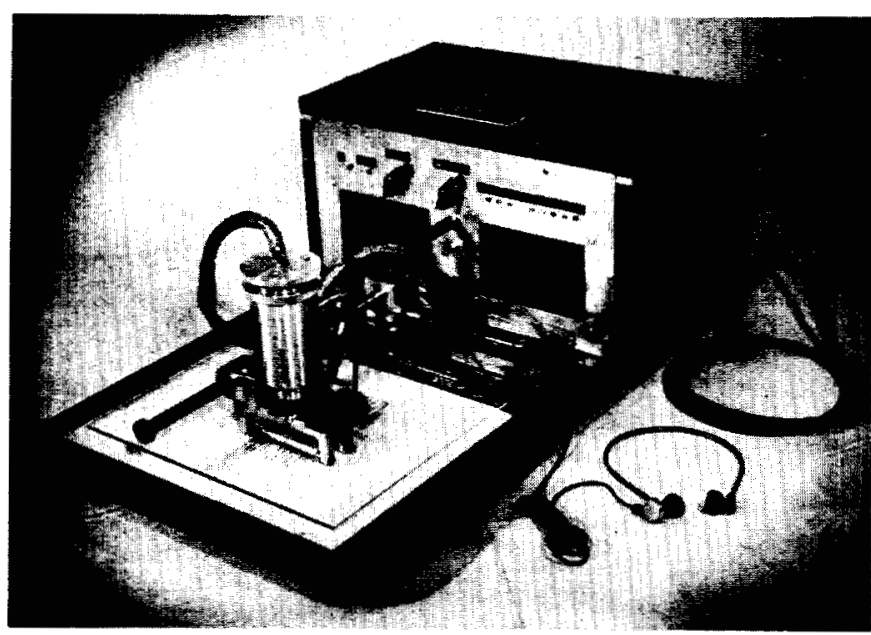

Fig. 5. The Lexiphone: a direct-translation reading aid which generates a complex nonspeech audio output that the reader must be trained to understand.

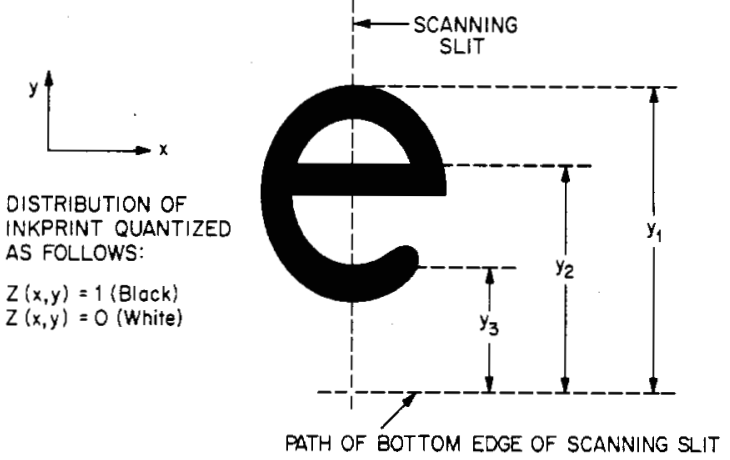

Fig. 6. An illustration of the processing algorithm of the Lexiphone. $M$ is the number of black areas in the field of the scanning slit.

at the University of British Columbia, is an example of this approach (see Fig. 8). The input to this reading aid consists of 54 photosensors arranged in a one-dimensional array that is manually scanned across the line of print. This large number of photosensors insures that the alphabetic images are transduced with adequate resolution and permits a tolerance in tracking accuracy equivalent to the height of a small lower case letter.

Beddoes' reading aid, shown in Fig. 5, has an auditory output which is produced by a frequency-modulated squarewave generator. The algorithm for the modulating signal is given by

$$
F(x, y)=K\left[y_{1}(x, y)+\sum_{r=2}^{M}\left\{y_{1}(x, y)-y_{r}(x, y)\right\}\right]
$$

where $F$ is the modulating signal, $y_{1}$ is the distance from the bottom of the scanning slit to the top of the letter, $y_{r}$ is the distance from the bottom of the scanning slit to the $r$ th white-black transition (from top to bottom), and $M$ is the number of black areas in the scanning field.

This transformation is illustrated in Fig. 6 and is based on the well-known fact that printed text can be read visually with little difficulty if only the upper outlines of letters are exposed. The thickness of the strokes making 
up the letters does not affect the value of $F$ and a change in the vertical alignment of the slit does not change the output "melody," but only alters the "key" in which it is heard. The transformation of (1) produces similar F's for the letters " $M$ " and "Y," but this ambiguity is removed by signifying each "riser" in the printed letter with a characteristic sound $12 \mathrm{~dB}$ louder.

Ten Lexiphones have been built, and at least one subject is currently reading with the device at $40 \mathrm{wpm}$.

Taking into consideration the economic status of potential users, direct-translation reading aids appear at the present time to offer the best prospect of providing individual access to print at a low unit cost. For this reason it is important that the factors controlling the reading rates achieved with direct-translation reading aids be determined and remedied if possible. Many interacting factors are involved. Among these are the limitations which have been noted earlier, namely those imposed by the physical properties of the sense organs and perceptual processes. In addition, the spatial resolution afforded by the input transducer may play an important role as it does in vision. But present knowledge of tactile perception is not sufficiently detailed to permit the confident prediction that image resolution spanning several letters will increase reading speed. This possibility must be explored experimentally.

\section{Current Research: Print Recognition Machines}

The machines described in the previous section have the inherent disadvantage that their outputs present the reader with a difficult perceptual-motor task which he must be trained to perform. To their credit is the fact that they are designed for production at low cost. On the other hand machines which attempt to exploit well-established perceptual skills invariably require a print recognition capability which leads to one of three main forms of output: braille, speech, or spelled speech. The characteristics of braille have already been described. Speech, which can be implemented in one of several different ways, will be described later in this section. The type of spelled speech, proposed for use in reading machines, is not in the same form as would be generated by a speaker. The spelled speech developed by Metfessel [59] and others consists of an alphabet of spoken letters selected from special contexts and edited so that the essence of each letter's sound identity is retained within a time interval of $140 \mathrm{~ms}$. Thus word sequences can be played more rapidly than normal voiced spelling and reading rates from 80 to $100 \mathrm{wpm}$ have been claimed.

The automatic recognition of optical characters has been in commercial use for a number of years [60]. These applications, developed for the Post Office, the banking industry, and the military, all involve large volume, high speed operations requiring high accuracy over a well-specified range of characters or type styles. In contrast, the performance requirements for a personal print-recognition reading machine for the blind do not demand high speeds (200 wpm would be adequate in the case of a speech output) or extreme accuracy (up to 1 percent error may be tolerated). Relaxation of many of the performance criteria applied to commercial machines would lead to reductions in cost. However, threatening to increase costs is the fact that a blind person wants to read a much greater variety of documents than are customarily encountered in commercial applications, which means that the character recognition system must cope with a wide range of type fonts, inks, printing methods, papers, and formats. The net result is that a higher performance character recognition capability may be required in order for the overall reader-machine system to exceed the performance levels achieved with direct-translation reading aids.

Designers of commercial character recognition systems have long realized that several hundred image points from a letter-space are necessary for high recognition accuracy, thus these machines are characterized by a large input bandwidth. Typically a flying spot scanner is used to acquire the character image. This is followed by contrast enhancement whereupon the signal is subjected, in sequence or in parallel, to a range of discriminant functions which can number 50 or more. Statistical techniques involving the computation of likelihood ratios for the outputs of the discriminators can be utilized, and on the basis of a given set of costs and rewards associated with each decision, the optimum output signal can be selected. Flexibility in the selection of decision criteria to meet different type styles is achieved by maintaining a high channel capacity throughout the machine and permitting the use of many discriminators. In practical situations, even in large volume machines, several compromises must be struck, and in the design of low-cost recognition machines, the need to make such compromises is particularly severe. In machines for the blind, the input bandwidth is curtailed, for purposes of economy, to such a degree that image resolution is of questionable adequacy (in one case fewer than 60 points within the character space are sampled [30]). In addition, for the same parsimonious reasons the discriminant functions are usually applied as closely as possible to the input of the system and their outputs are binary rather than continuous functions of likelihood. The weighing of evidence by Bayes rule procedures based upon a priori statistics of the language are also not employed. These machines, having lost a great deal of flexibility, have to be nevertheless prepared to function with a wide range of type styles and print quality from books to newsprint. The problems are formidable.

One of the efforts being made in the development of character recognition for the blind is the work being carried out by Mauch Labs [30], [61]. The Mauch Cognodictor shown in Fig. 7 consists of an optical system contained in a hand-held probe which focuses the printed characters onto a specially structured two-dimensional photocell array of only 12 sensors shown in Fig. 8. A magnification adjustment is provided giving a range from 7 to 36 point type. Tactile stimulators are provided on the probe to facilitate adjustments to type size and to permit tactile identification of certain numerals and characters that elude the recognition system.

The discriminant functions of the machine are applied in sequence at the input in the form of a multiple snapshot 


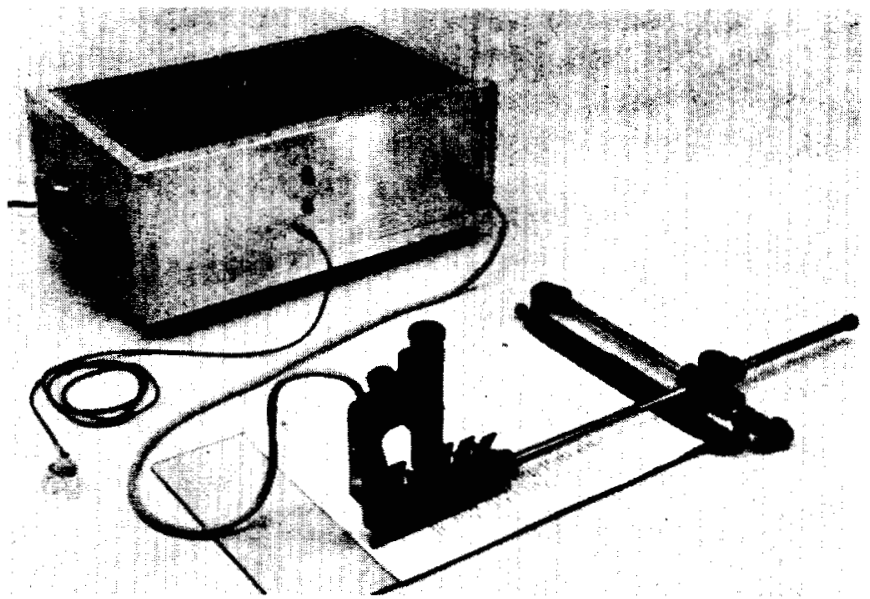

Fig. 7. The Cognodictor: a recognition reading machine providing a spelled speech output. Input is provided by a Digitactor probe fitted with the photocell array depicted in Fig. 8.
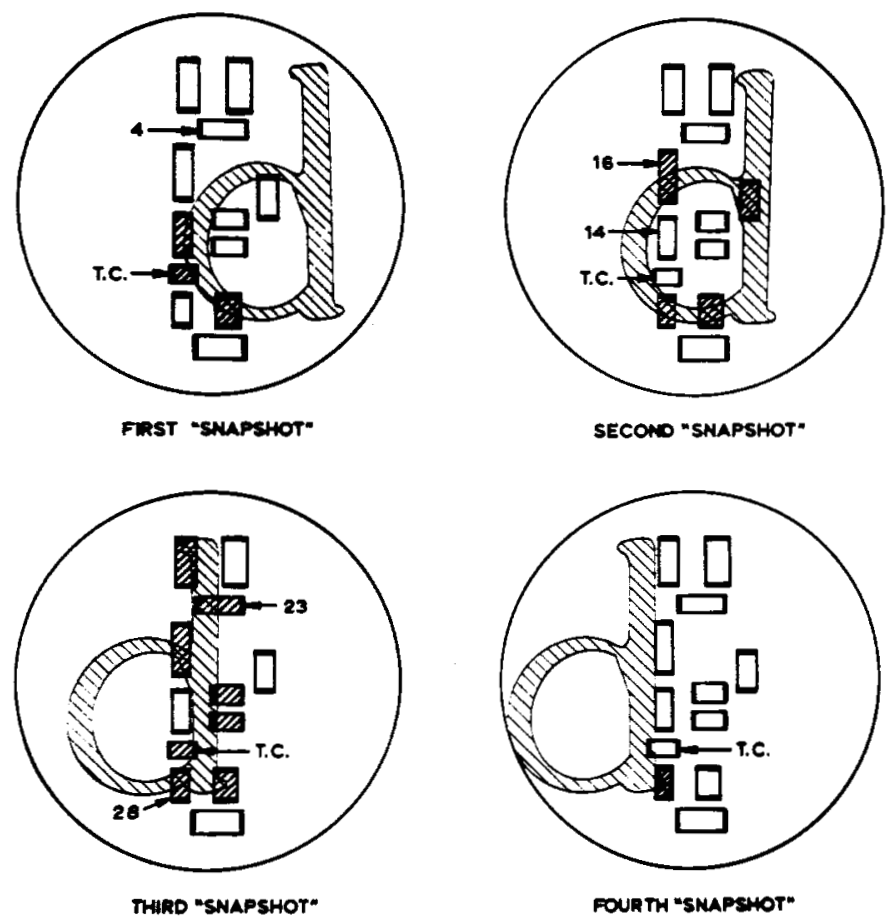

Fig. 8. The array of photocells designed to intercept distinguishing features of printed characters shown scanning the letter " d." Photocells used for the tactile output are not shown. The direction of current flow is indicated by the bold lines representing electrodes. The trigger photocell initiates a snapshot when the limb of a character is intercepted and again when it is removed. Information is stored in different groups of memory units and read out and reset when the character has passed.

procedure. As a printed character image is scanned across the optical input it stimulates a trigger cell which senses the character position and initiates the snapshots. The remaining eleven specially structured cells are shaped in such a way as to be capable of detecting distinctive features of the characters which are largely independent of stroke width and type face. Output from these cells is converted into a five-bit code which specifies one of 31 prerecorded spelled speech letters. Buffer storage of up to eight letters is provided between the recognition unit and the output device which utilizes a continuously rotating drum on which the spoken letters are recorded optically.

The Colineator is provided to assist in maintaining manual tracking within the $13 \mathrm{mil}$ limit required by the system. For characters which the machine is unable to identify an additional array of eight photocells, set in a vertical line, is connected to a column of tactile stimulators located on the probe. With this back-up device the reader can attempt to tactually identify delinquent characters. The objectives are an accuracy of 90 to 95 percent and a reading rate of between 80 and $90 \mathrm{wpm}$. However, a recent report [62] indicates that given the specified tracking tolerance, recognition accuracy, and form of the output, the maximum achievable reading rate may be significantly less than 80 to 90 wpm.

One laboratory prototype model has been built and, under informal conditions using this machine, reading speeds of 20 to $25 \mathrm{wpm}$ have been cited [30]. However, no precise measurement of reading rates has been made and there are no reports indicating such technical features as the peak recognition speed and accuracy. During 1969 three production prototype Cognodictors were built using integrated circuits and these machines are now undergoing a shake-down evaluation. This project has been under way for a period of ten years during which time the recognition technique has evolved. Demonstration of a working machine may be expected soon.

Somewhat more flexible is the system being built by Ingham, Lee, Mason, and Troxel [63], [64] in the Research Lab of Electronics at M.I.T. This machine is based upon a PDP-9 computer associated with a special-purpose processor unit which is responsible for carrying out automatically such functions as line and character acquisition. The primary input data are obtained from a flying spotscanner, providing much more resolution than the Cognodictor. This scanner executes a contour-following algorithm originally designed by Clemens [65] and which is contained within the special-purpose processor. As the scanner proceeds around the contour, a sequence of coordinates is transmitted to the computer which then calculates "certain critical dimensions" of the character such as its height, width, and internal structure. From these measurements a quantity termed the "character signature," consisting of a 30-bit word, is derived and sought in a table established during a preliminary "learning" process. From this table, if the signature is already registered, the identity of the character can be determined directly. Output signals representing recognized characters can be employed to select prerecorded spoken letters and thereby generate spelled speech [66]. Alternatively the signals may be processed either by a braille translation program or by an algorithm designed to produce synthesized speech.

The braille translation program leads to the production of embossed braille of moderately good quality, but which is still subject to the already referred to errors arising from the occasional incorrect application of contractions across syllabic boundaries. Synthesized speech is produced from an input string of phonemic symbols each accompanied 
by its appropriate stress. The phoneme symbols govern the selection, from the computer memory, of the correct control signals linked together by linear interpolation. These signals are then used either to drive a hardware speech synthesizer or its analogue simulated on the computer. A vital intermediate stage between the recognition and the speech production, however, is the grapheme to phoneme translation program reported by Lee [67]. This program performs a subunit classification at the orthographic level, applies certain rules of recombination, and forms the phonemic units. Stress factors are also derived from a syntactic analysis of the text and used in the control of the speech synthesis program.

It is apparent from their approach and the compromises that they have chosen to make that the system envisioned by the M.I.T. group represents an effort at producing a complete reading machine with speech output which, although not of the finest quality, will nevertheless be sufficiently intelligible to provide acceptable service. However, their machine, being somewhat more ambitious than that designed by Mauch Labs, is likely to be more expensive to produce. Therefore it appears at present to be unlikely to fill the role of a personal reading machine. It appears probable that such a device would be suitable for use as a library facility.

Another program located at the Haskins Labs [68], [69] is concerned with specifying ways of obtaining intelligible spoken output from input information received from a print recognition machine. Several alternative systems are being examined. One method, referred to as compiled speech, uses a dictionary of 7200 of the most frequently used English words [70] in addition to the letters of the alphabet, all in spoken form. As the incoming letter sequences arrive, grouped into words, the appropriate outputs are sought in the dictionary and, if located, are delivered as word-by-word replayed speech. If a required word is not one of those available in spoken form it is heard spelled letter by letter. In a naturally spoken sentence the pitch and stress of the voice are important cues which the listener utilizes to aid comprehension. In an endeavor to go part of the way toward meeting this need for intonational cues the dictionary contains words each of which bear the stress and intonation appropriate to the function it most often serves in a sentence. For example, a noun usually receives the greatest stress in a spoken sentence, and hence nouns are stored with high stress. Verbs and adjectives, on the other hand, are stored with medium stress, while conjunctions, prepositions, pronouns, etc. have low stress.

Yet another system under study uses speech that is synthesized under computer control. Input to this system is provided in the form of phoneme symbols and corresponding stress markings [71]; the output to a hardware speech synthesizer is a set of control parameters that are computed from rules first described by Liberman et al. [72]. These rules for synthesis employ tables of normative spectral configurations and algorithms for combining them into sequences which take account of the other units in the se-

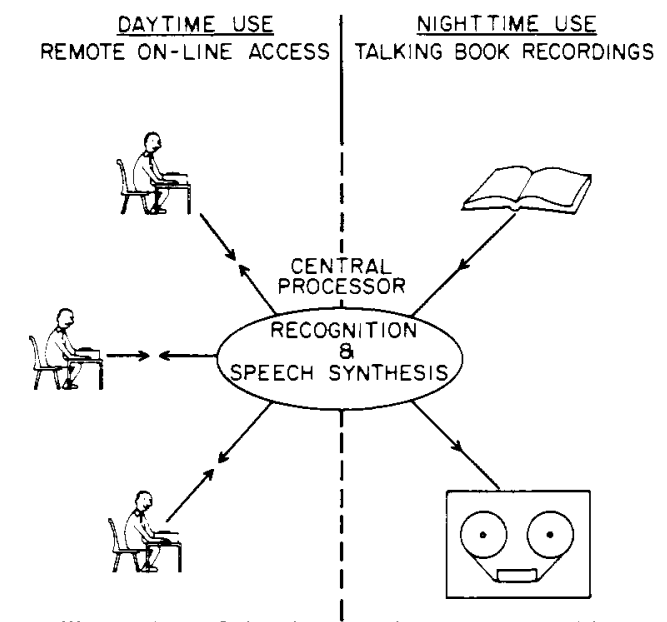

Fig. 9. An illustration of the dual service in which a high speed timeshared computer system can be engaged. During the day an individual reading service via telephone lines could be provided. At night Talking Book recordings could be made at high speed.

quence, i.e., of the local context. This is necessary to achieve at the synthesizer smooth naturalistic coalescence of the output sounds and to approach normal speech as closely as possible. An alternative to computation is the use of a stored dictionary of control signals corresponding to printed words. The choice between computing and storing the control parameters involves tradeoffs among such factors as speed, quality, and the cost of memory and computing power.

The techniques developed and adopted by the Haskins Labs in the speech synthesis work are among the very best available and no unavoidable compromises of speech quality are being made in their application to a reading machine. But it is clear that these procedures, either for speech compilation or speech synthesis, require the type of complex circuitry which is found in medium or large size computers.

The inherent bulk and expense of such systems as they exist today leads to the conclusion that speech outputs should be most appropriately applied to the task of providing, in conjunction with a high-speed print recognition system, reading services in large libraries or to a number 'of subscribers within a city in a time-sharing mode. In addition such a system could provide a high-speed talking book service during off peak hours (see' Fig. 9). Although the recognition unit would be likely to limit the range of recognizable type styles of the more common fonts, it is certainly within the capability of current technology to build a centralized system which could generate speech, perhaps significantly short of perfection, but nevertheless understandable with practice at rates of between 200 and 300 wpm. Given the resources to implement such a scheme it is to be expected that the initial steps would involve an evaluation of the cost, speed, and efficiency of the various recognition and speech generating algorithms followed by pilot studies of a prototype system carried out in a major city. However, given the current levels of support for sensory-aids development it appears unlikely that this phase will begin for several years. 


\section{Current Research : Mobility AIDS}

The situations in which a mobility aid is required to function are considerably more varied than those confronting a reading aid. Besides the vast differences implied by rural-versus-urban environments, various weather conditions, and various types of terrain, blind people have widely different mobility needs. For example, an individual may be simply interested in getting from one location to another in the most efficient manner possible without receiving extraneous information about the environment he is traveling through. Another individual may wish to explore or search his environment, with travel to a particular destination being a secondary goal [73].

Faced with such a large array of variables it perhaps is not surprising that a number of writers have pointed out the need to structure research activities around a theory of mobility [74], [75]. However, although it is possible at the present time to point to the kind of questions that the theory should be able to illuminate [76], the present state of knowledge is insufficient to provide firm guidance. Clowes [75] has suggested that the best way in which this knowledge can be sought is experimentally by simulation techniques described by Mann [77].

In an effort to establish a base line against which all improved methods of mobility and reading could be measured, the Government Social Survey in England undertook in 1965 to sample one in twenty of the registered blind in the age group 16 to 65 and one in sixty of those aged 65 to 79 and to determine their current mobility and reading habits. The results of this survey were reported by Gray and Todd [7] who indicated that different levels of mobility performance were very closely related to basic characteristics of the blind population and that an improvement in their independence necessitates the availability of a considerable variety of methods of training and rehabilitation. Responding to these conclusions Leonard and Newman [78] have been evaluating the usefulness of various kinds of tactile maps in helping blind travelers acquire new routes.

In another attempt to discover the mobility needs of blind people, Liddle [79] has taken the direct approach of seeking opinions and comments. The report of his study contains a summary of those obstacles of most concern to blind travelers. These were bicycles, roadwalks, posts, prams, toys, ladders, scaffolding, overhanging branches, awnings, and tricycles. ${ }^{4}$ Most of these obstacles are either relatively small or they present a small cross-sectional area to a person's path. Most are also movable and thus occur in unexpected places and at unexpected times, even on familiar routes.

In the face of a constantly changing environment it is imperative that a mobility aid give adequate warning and reliable service. The potential for bodily injury inherent in undetected obstacles reduces the value of a mobility aid that only works most of the time instead of all of the time. It is

\footnotetext{
${ }^{4}$ However, it should be remembered that this survey was taken in England and the results, particularly with regard to the automobile, may be expected to be quite different in this country.
}

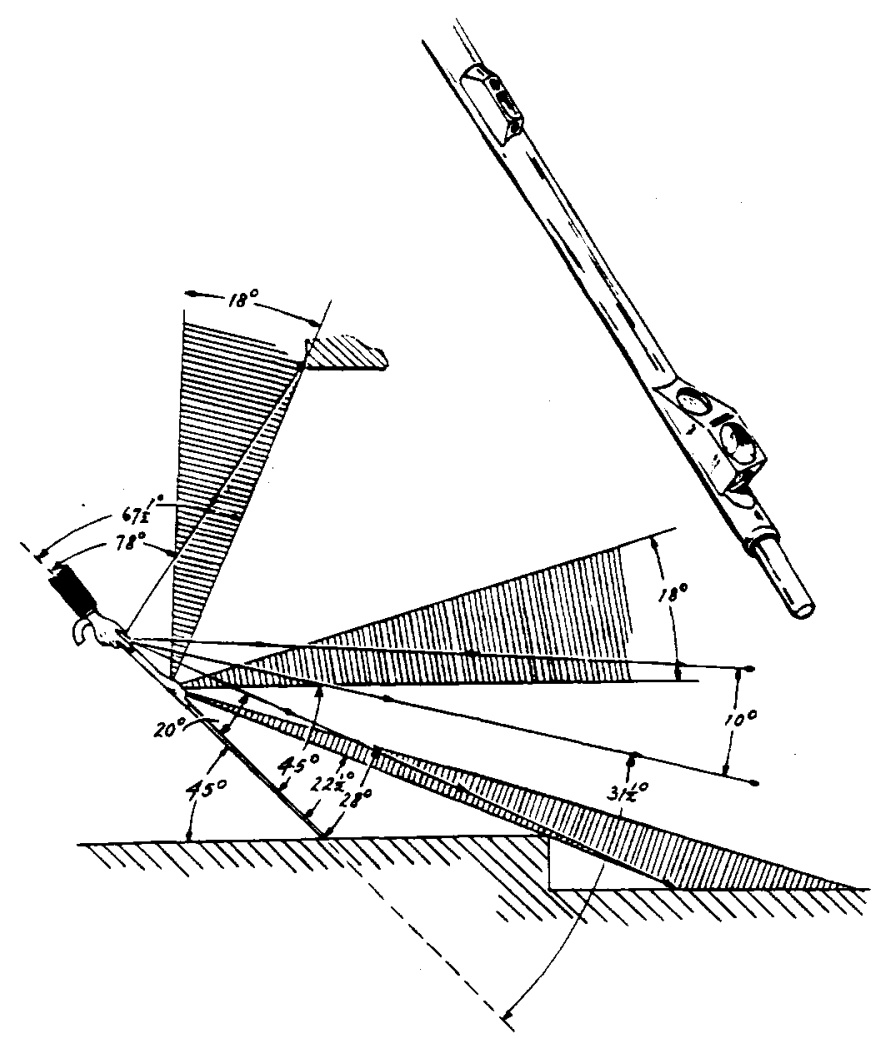

Fig. 10. An illustration of the "ranging by triangulation" technique applied in the Bionic cane. The hatched areas indicate the $18^{\circ}$ solid cone of reception of the three receivers. The three laser beams are emitted from a point close to the subject's hand.

difficult to develop confidence in a device that warns one of most obstacles but fails to give a warning for an infrequent but nevertheless dangerous obstruction. In this regard the reliability, simplicty, and effectiveness of the cane, over the area it is commonly used to explore, is difficult to surpass with an electronic system, and most current mobility aid programs are therefore aimed at augmenting the cane rather than replacing it.

During the past 25 years over twenty guidance devices for the blind have been built. These have been based on a variety of principles and have been aimed at the solution of various aspects of the travel problem. There are at least three currently active research and development programs on guidance devices, and these are about to be described. While there have been some guidance devices built that operate on ambient light reflected from the obstacle, all three active programs are primarily concerned with systems that radiate energy, either electromagnetic or acoustic.

For the past eighteen years Haverford College and Bionic Instruments Inc. have been engaged in the development of an electronic travel aid [80], [81]. The major device currently under development and testing is a "laser cane"; the Bionic cane. This device has had several predecessors which, while marginally useful, have led to the current design philosophy, i.e., to apply integrated circuit technology to expand the usefulness of an existing mobility aid. Thus the triangulation ranging technique (see Fig. 10), developed in earlier devices, was combined with the Hoover 


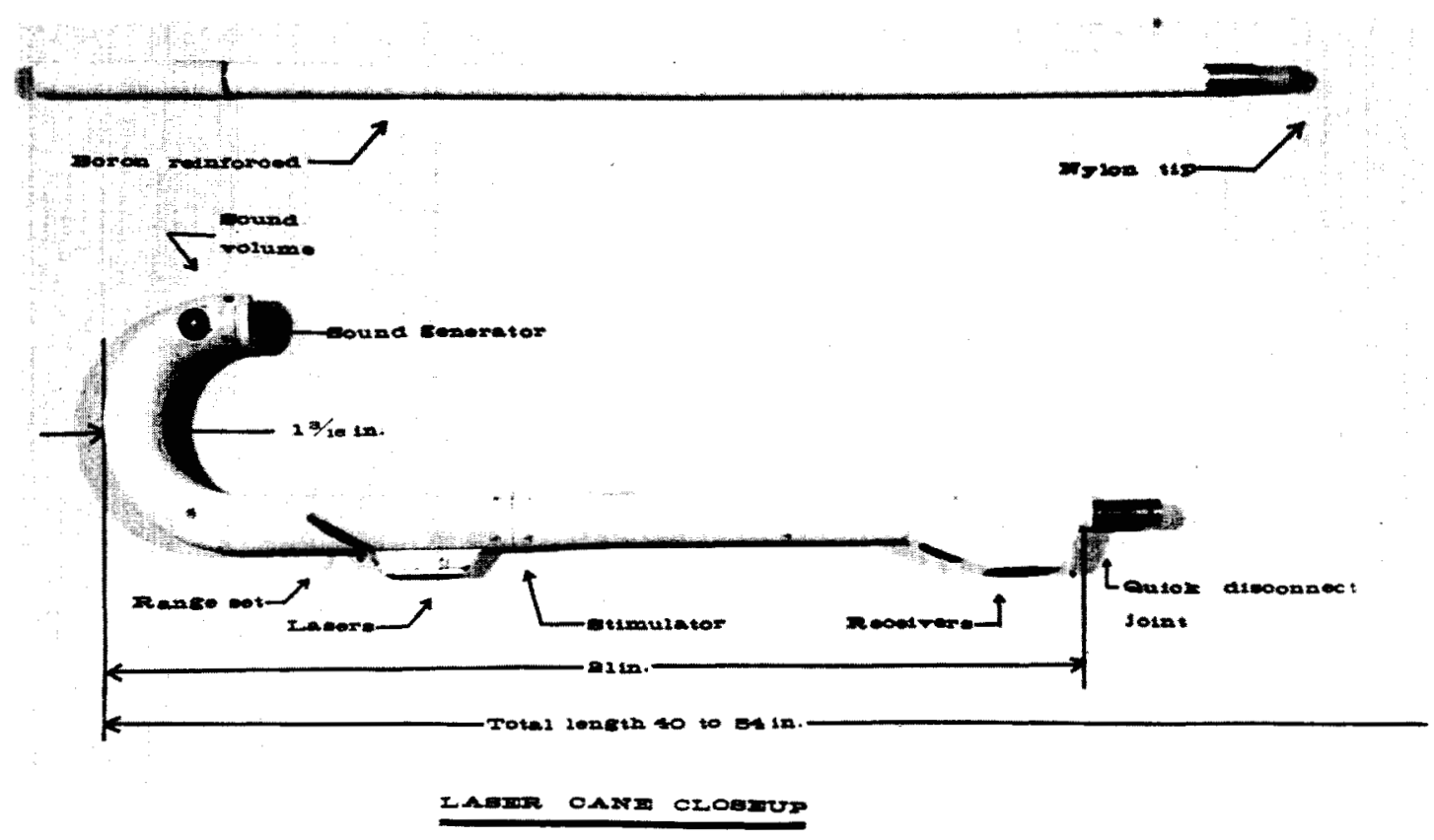

Fig. 11. The Bionic cane seen in detail.

long cane [82]. This research has led to the design shown in Fig. 11 of which ten copies are presently being tested.

The Bionic cane combines three lasers, associated photocells, and electronic systems into three optical ranging systems. One system is responsible for detecting objects ahead of the man and is intended to permit relaxed walking without fear of hitting obstacles or striking people's legs. It also has an adjustable ranging feature for the detection of more distant objects which may represent significant landmarks useful in navigation. The second system projects forward and downward ahead of the cane tip to provide assurance of an extended level walking surface. The third laser beam points upward to detect overhanging branches, signs, casement windows, or other above-the-waist hazards.

All three receivers (forward, overhead, and downward) operate a single tactile stimulator in contact with the index finger. In addition a small loudspeaker in the handle emits a high-pitched sound when an overhead obstacle is encountered, no sound for forward obstacles, and a lowpitched tone for surface hazards.

Some early concern over the possible danger of the lasers to sighted bystanders has now been dispelled, and it is to be hoped that the current tests will prove this long awaited development to be at the point of practical utility.

A second currently active guidance device program is that pursued by Kay [83], [84] at the University of Canterbury, New Zealand. In this program a guidance device has been developed which is based upon an ultra-sonic sonar system. The system consists of two independent frequency-modulated channels utilizing a transmitter radiating into a $50^{\circ}$ solid angle and two receivers mounted within a spectacle frame shown in Fig. 12. The output signals are directed to the user binaurally, the purpose being to indicate both the distance and direction of an object simultaneously over a wide arc of "view." Housing the transmitter and receivers

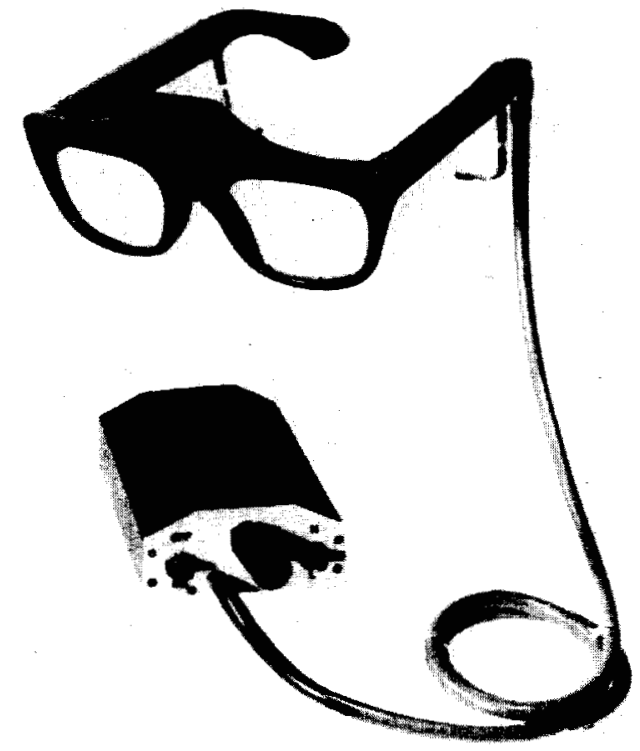

Fig. 12. The Ultrasonic Spectacles designed by Kay. Transmitters and receivers are located at the bridge of the nose. Batteries are located in a vest pocket carrying case.

in a pair of spectacles represents a later refinement of the technique originally applied to a Sonic Torch; a hand-held monaural device about the size and shape of a medium flashlight.

In operation the ultrasonic spectacles transmit a beam of energy which sweeps from about $90 \mathrm{kHz}$ to $45 \mathrm{kHz}$ in the course of a short pulse. The received echo is mixed with the transmitted signal and the resulting difference-frequency signal is conveyed to the user through earphones. For reflection from a stationary object the difference frequency is constant and proportional to the range of the reflecting object. The amplitude of the displayed signal is a function of the reflecting properties of the object as well as its dis- 
tance, and hence the relative intensity of the signals reaching the two ears and their time of arrival indicate the direction of the reflecting object. The complex array of objects present in the typical environment leads to the generation of a similarly complex audio pattern. Contained in the philosophy of the Kay device is the underlying assumption that the user, with proper training, will learn to distinguish the important from the irrelevant information. Only careful evaluation can determine whether this assumption has any validity.

There have been a number of evaluations of the Sonic Torch, which has been available commercially since 1965 . Juurmaa [85] found little improvement in the performance of a group using the torch over a control group without the torch when the tasks were discriminating material and judgment of fine differences in size. Similar conclusions were drawn by Leonard and Carpenter [86]. Evidently, under ideal conditions, normal unaided human echolocation abilities, studied by Rice [87], Wilson [88], and others, are only marginally supplemented by information from the torch. Distance estimation was shown to be the most suitable task for the ultrasonic aid, and the performance of the group using the torch did not deteriorate as much as the control group in more difficult simultaneous discrimination tasks.

Objective tests of this type apparently do not examine every aspect of the complex interactive relationship between the device and the user, for, in contrast to these cool, cautious conclusions, it must be pointed out that in several instances, user acceptance of the Sonic Torch has been enthusiastic [89]. A possible reason for this may be that the aid reduces the anxiety of the traveler or the effort he makes and that both of these factors eluded the measurement techniques that were used. The results of recent attempts to develop suitable measures of the stress that mobility places upon blind travelers (based upon recordings of heart rate) have been reported by Wycherley and Nicklin [90]. However, despite the mixed reception met by the Sonic Torch, there appears to have been a sufficient number of factors in its favor to sustain optimism that the newer binaural device will be even more useful. A field trial of 200 of the spectacles is scheduled for 1971 with six organizations participating.

The third currently active guidance device program is based on a device developed by Russell [91] in conjunction with the M.I.T. Sensory Aids Evaluation and Development Center. This device is called a Travel Pathsounder. It is worn at chest height by a neckstrap and is shown in Fig. 13. The display is auditory and is effected by two small loudspeakers on the neckstrap. The ultrasonic beam explores the volume through which the user's head and shoulders will pass as he takes the next few steps. In contrast to the Kay aid which makes the user responsible for a considerable amount of signal processing, the Russell aid assumes that only the existence of obstacles in the immediate path is of importance. Thus when no object is detected within 6 feet there is no audible sound emitted by the device, but as an obstacle enters the 6 feet range, a ticking sound is broadcast. The ticks become louder at closer ranges until at 30 inches the signal changes abruptly to a beeping sound.

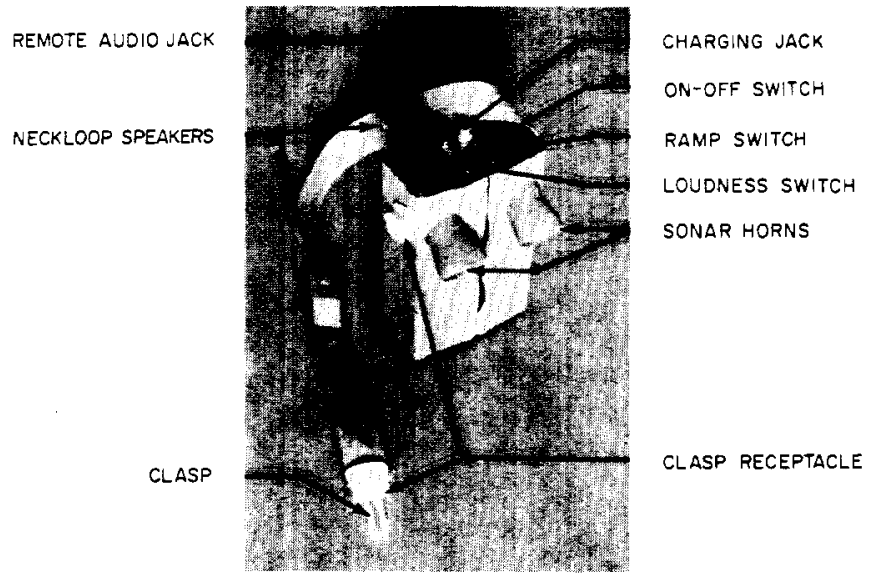

Fig. 13. The Travel Pathsounder designed by Russell. Transmitter, receiver, electronics, and power source are all enclosed within a single case worn about the neck.

Thirteen of the Russell Travel Pathsounders are presently being evaluated at six institutions nationwide. A formal Training Manual [92] is employed. Several blind travelers have utilized the device daily for a year.

The position at this point of time is particularly interesting because the three projects described here appear to be close to achieving their original technical objectives. The near future will determine how relevant and important these objectives will be in the life of a mobile blind person.

\section{VisuAL SUBSTITUTION SYSTEMS}

The widespread familiarity with television has spawned the belief among many laymen that it might be possible to design an artificial eye after the manner of a television camera, connect it to the optic nerve of a blind person and enable him to see. The underlying misconceptions of the anatomy and function of the visual system which this idea reveals are too numerous to detail here. Better neurophysiological support can be provided, however, to the feasibility of bypassing the optic nerve and providing direct stimulation of the visual cortex.

Early work by Foerster [93] and Krause and Schum [94], who studied the effects of electrical stimulation of the exposed occipital lobes, revealed that the stimulation of points on the striate cortex led to the sensation of discrete spots of light (electrophosphenes) whose location in space bore a point to point relationship with the cortical area being stimulated. More recently, Brindley and Lewin [95] reported the results obtained from stimulations with an array of electrodes in contact with the medial surface of the occipital pole of the right cerebral hemisphere and falx cerebri of a blind subject. Radio receivers located underneath the scalp and outside the skull were connected through a trephine hole to an array of 80 electrodes located inside the skull (see Fig. 14). In this way a permanent breach of the scalp was avoided and the stimulus signals were conveyed through the skin by radiation from transmitters appropriately tuned to the frequencies of the individual receivers. Of the original number of implanted electrodes, less than half functioned successfully, but despite this disappointment, encouraging data were gathered which indicated that predictable simple patterns could be generated with 4 or 5 


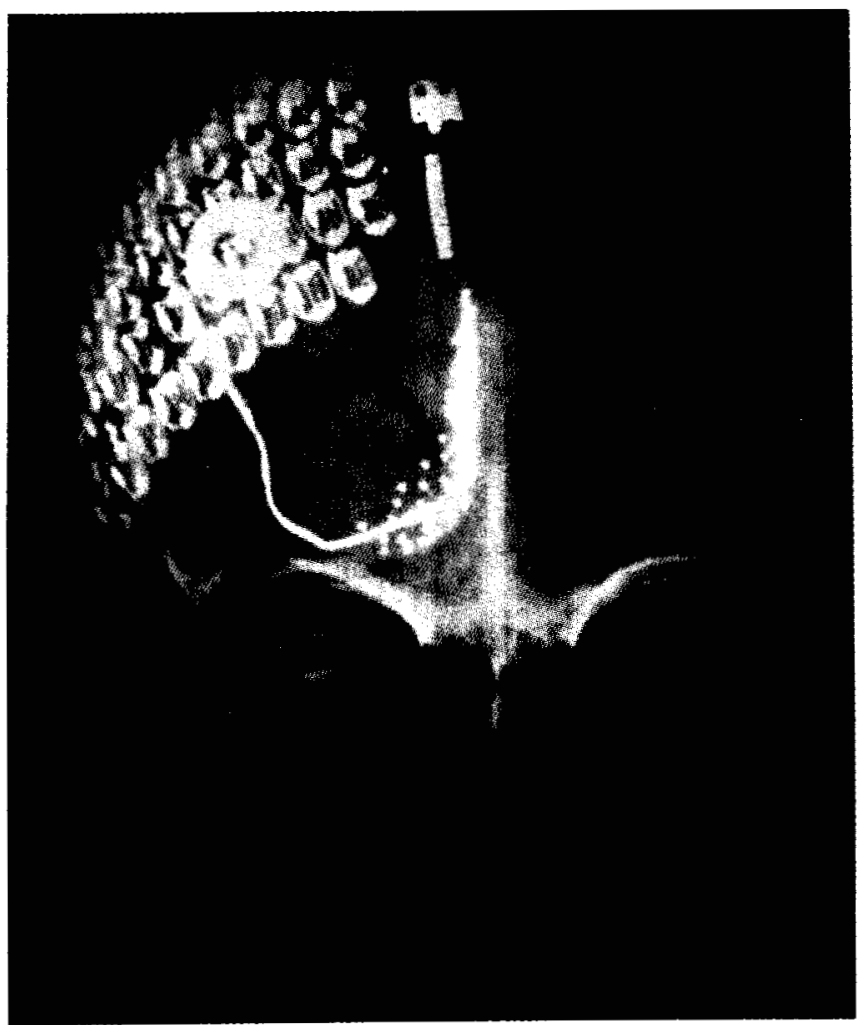

Fig. 14. An X-ray photograph of the head of the female subject employed in Brindley and Lewin's experiments. The receivers can be seen in the top left hand corner of the figure. The electrodes are located beneath the skull. (From J. Physiol, vol. 196, 1968, with permission.)

electrodes and identified by the blind patient. Ordinarily the electrophosphenes disappeared immediately when the stimulation ceased, but the aftereffects of strong stimulation sometimes persisted for up to two minutes.

Among the major questions that remain unanswered are, can a sufficient number of electrodes be implanted to achieve resolution of a visual image; how closely can they be placed and still be resolved; what interaction effects are likely to occur when many electrodes are simultaneously stimulated; and how long can an array of electrodes remain functional? Brindley and Lewin are optimistic that these problems can be solved and a successful prosthesis will eventually be developed "that will permit blind patients not only to avoid obstacles when walking, but to read print or handwriting, perhaps at speeds comparable with those habitual among sighted people." A similar view has been stated by Schimmel and Vaughan [96] who believe that it is theoretically possible to create a grid of up to 4000 points which can be implanted in a human subject.

The emphasis on human experimentation rests on the fact that to a greater degree than is usually experienced in experimental surgery the preliminary use of animals is sharply limited by the severe difficulty of evaluating their visual performance. An experimenter could possibly learn as much in one hour from a man fitted with a prosthesis as he could discover in a year of experimentation with monkeys. Nevertheless, there are some risks involved and, as a result, some opposition to the use of human subjects. On the other hand, in common with other radical surgical procedures, the work on humans has wide popular appeal.
Strongly supporting work on electrical stimulation of the cortex is the implication, which goes well beyond the claims made by Brindley and Lewin, that these measures will ultimately restore sight, essentially in the form experienced by sighted people. However, the scientific evidence suggests that the "visual experience" will be much more restricted and may be qualitatively different. A more revealing comparison would result if direct stimulation of the visual system were seen as creating a coarse grained shadow-play lying somewhere between vision and providing access to a sensory surface analogous to a previously unavailable area of the skin. This skin-like surface, albeit with potentially greater sensitivity and greater resolution, may be capable of providing an additional means of supplying information input to the nervous system. Experience has shown that the costs of the pecessary research, development, and implementation will be high, and yet the potential patient population can be only a very small fraction of the blind community. Bearing in mind the all too familiar potency of dramatic surgical procedures in attracting public atttention and public money, it is to be hoped that the prospects and limitations of a direct cortical stimulation project will be weighted carefully. Moreover, if it is to be supported by sensory-aids research funds, it is to be hoped that this will not be at the expense of the many other vital programs that have been noted in this paper.

In addition to direct cortical stimulation there are several active research projects aimed at a "general purpose" visual aid or visual substitution system utilizing various areas of the skin. One such system is that reported by Starkiewicz and Kuliszewski in Poland [97], [98] who coupled a 120-photocell array to a corresponding array of transistor-energized solenoids used for tactile stimulation of the forehead. Bliss and Gardiner [99] have also built portable optical-to-tactile image conversion systems with arrays of 144 phototransistors driving 144 tactile stimulators appropriate for scanning the environment. Recently Bachy-Rita et al. [100] have described a television system comprising a Vidicon camera functionally driving 400 tactile stimulators in the form of a 20 by 20 matrix mounted on an invalid-chair, (see Fig. 15) and placed in contact with a teninch square of the subject's back.

While these systems are interesting from a research standpoint, none is useful for either reading or mobility in their present form. Their most severe shortcoming is in image resolution. With only a few hundred points it is impossible to have both an adequate level of resolution and a reasonable field of view in a direct-translation system. Commercial television, which displays a picture of far poorer quality than the capabilities of normal vision, nevertheless provides the equivalent of approximately 250000 points. While it is unknown how many points can be usefully displayed on the skin, it is unlikely that a number as large as this can be accommodated.

Even if the resolution and field of view difficulty can somehow be circumvented, there are many remaining problems. For example, the present optical-to-tactile systems provide stimulation which is either on-or-off (i.e., no "grey scale"). They are also monocular, and the range of ambient light for 


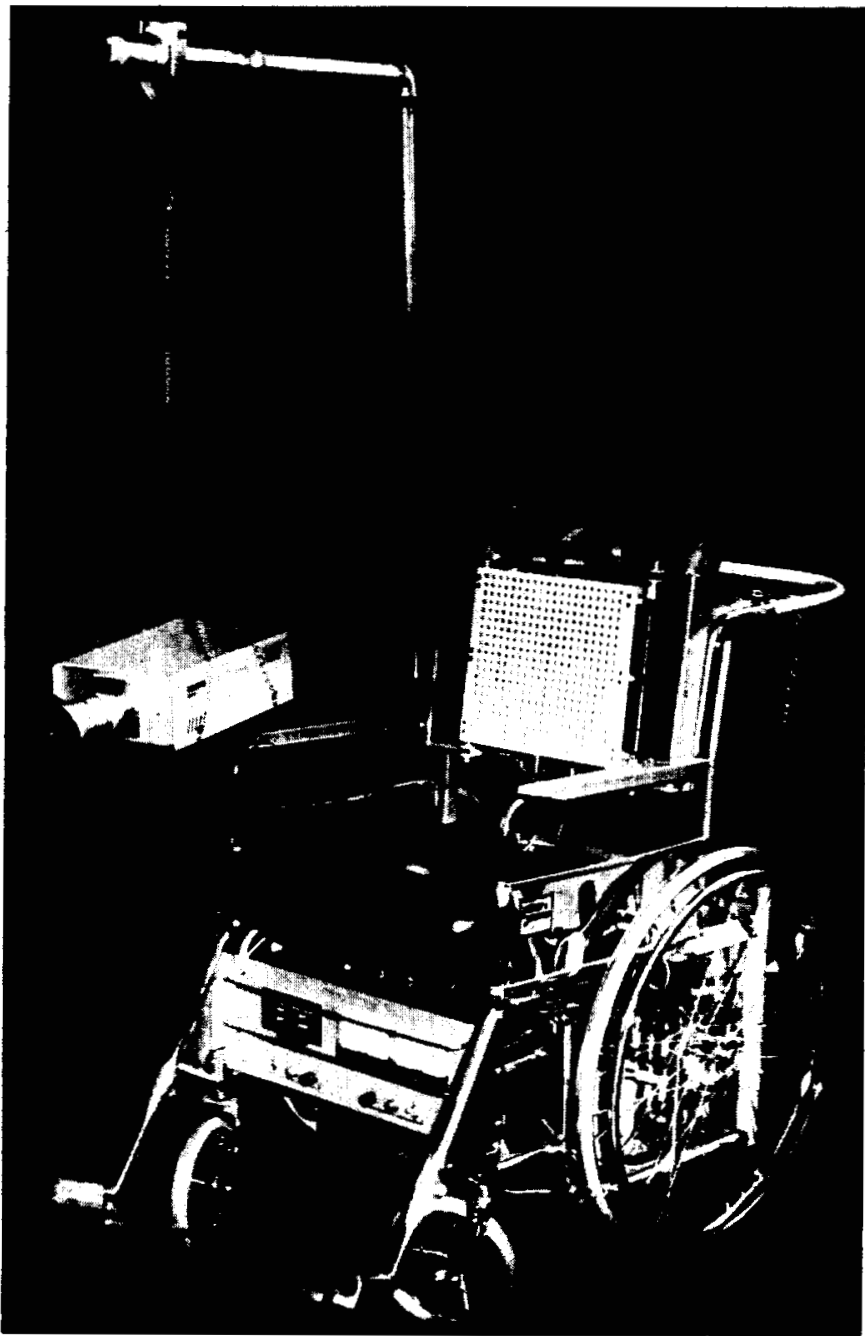

Fig. 15. The visual substitution system of Bach-y-Rita et al. [100]. A television camera is supported by an overhead member. The 20-by-20 array of tactile stimulators is located in the chair back.

satisfactory operation is limited. Looking into the future however, it may be possible to combine such an optical-totactile image conversion system with an ultrasonic mobility aid and certain forms of image processing. If such a combination could be made with a highly compatible display and could also be made small and portable, there is a possibility that a very effective aid might be evolved. But the technical, psychophysical and economic problems that such a device would pose are numerous, and the prospects are not encouraging.

\section{The Evaluation of Sensory Aids}

In an earlier section of this paper we noted the fact that the trial and error approach to sensory-aid development made the continuous evaluation of performance a vital part of the research and development process. This is particularly true of mobility aids. The recognition of this fact has grown significantly during the last decade although the structure of research financing, which customarily supports research and development followed separately by evaluation, has tended to mitigate against a closer interaction between these activities. Evaluation of the utility of a device is one of the most difficult phases in its development.
Many complex factors, among them the experience and personalities of the subjects whose performance is under test, contribute toward the difficulties of evaluation. Most baffling to some observers are the cases in which the use of a mobility aid, for example, provides little or no detectable improvement in performance and yet the user will not hear of parting with it. Nevertheless, the recent trend toward more extensive programs of evaluation [101]-[103] but largely isolated from research and development activity, has shown signs of taking the first steps toward establishing a methodology which, when properly applied, can yield useful data [104], [76].

In an effort to meet the need for some mechanism for the evaluation and development of sensory aids, M.I.T. in 1964 set up the Sensory Aids Evaluation and Development Center (SAEDC). The early program of the SAEDC involved the examination of radio frequency compasses, folding canes, braille translation by computer, a high speed electric braillewriter, and other devices. The center has also been responsible for the organization of a number of conferences on various aspects of blindness rehabilitation. A close working relationship exists between the center and the M.I.T. departments of Electrical and Mechanical Engineering whose students, some of whom are blind, are involved in the development and preliminary evaluation phases of many of the projects. This relationship is still in the process of evolution, but the point appears to have been reached when the center will shortly prepare to extend the scope of its evaluation by initiating the larger scale production of those devices which have indicated potential merit.

The three most significant evaluation programs on sensory aids have all been carried out during the last 15 years. The first began in 1957 with the development of the Battelle reader which was the first of the modern family of instruments whose output resembled the sound produced by the original Optophone. An extensive sequence of training lessons was constructed and a total of 52 blind people participated as subjects. In their final report Coffey and McFarland [105] found that the average reading speed (of about ten wpm) fell as a function of an increase in size of the class. They concluded, however, that if adequate screening methods could be developed to select good potential students, this tendency could be arrested, and that about ten percent of the totally blind population might be trained to read at a minimum speed of $20 \mathrm{wpm}$.

The G-5 obstacle detector designed at Haverford College and Bionics Instruments Inc. was a predecessor of the current Bionic cane. An evaluation of this device, which utilized a single optical triangulation system, was reported by Deatherage [106]. He examined the performance of 26 subjects using both "customary aid" and the G-5 device. It was found that the G-5 was marginally superior in field trials although aided performance was found to be inferior on standard obstacle courses. The report concluded that personality variables were significantly related to the evaluation and that there was an evident need to develop screening methods or prescription criteria.

The Sonic Torch, designed by Kay, was manufactured in England, starting in 1964, and supplied to numerous or- 
ganizations for the blind. Evaluations were carried out concurrently by a number of teams, both in this country and abroad, and the results reported in 1966 at a conference held in London [101]. The difficulties of evaluation are clearly evident in these reports which describe data obtained under different conditions and often arrive at conflicting conclusions.

It is an initial premise of this paper that evaluation should serve two purposes: to derive measures of user performance comparable with those obtained with other devices or modifications of the same device, and to provide information that can ultimately lead to the production of better devices. A review of the reports on the Battelle reader, G-5, and the Sonic Torch evaluations reveals that, while some progress was made in establishing measures of performance, the results of these evaluations provided very little information that would be of help to the designer. Yet it is obviously desirable that this kind of information should be obtained. However, an important feature of these three evaluation programs has been their independence of the design and manufacturing processes. While it is possible to see some merit in this arrangement, it contains the weakness that the evaluation personnel are unlikely to be aware of the engineering compromises and arbitrary choices that have been made during the design and manufacturing phase. They are thus unable to address themselves to these questions and to evaluate and give guidance on whether the correct decisions were made.

A satisfactory compromise could be struck if evaluation were seen as being composed of two stages; the first in which the impact of certain technical decisions upon performance were carefully measured in close harmony with research activity; the second stage an independent evaluation concerned primarily with the measurement of performance criteria under field trial conditions.

The evaluation projects described thus far have represented independent, largely unrelated studies focused upon single devices fully engineered before work began. A radically different approach to the problems of evaluation has been proposed by Mann [77]. He states the opinion that the purely technical aspects of sensing the environment are largely realizable and that the major difficulties actually lie in the design of an effective display capable of providing the subject with the information he needs. Much of the time and effort spent in current sensory-aid development is consumed in the process of achieving such features as portability and reliability before the most uncertain aspect of the whole venture, the display efficiency, is put to the test. By the application of simulation techniques employing a digital computer and telemetry systems, Mann suggests that the properties of any given display mode could be evaluated without recourse to the hardware construction of an actual device. The flexibility in the design of new displays that this system would provide and the speed with which they could be put into effect and tested could significantly speed the progress of research in the sensory-aids field. It is significant that simulation methods of this kind have been used successfully on similar problems in space vehicle and aircraft technology for a number of years.

\section{COORDination of Research, DeVElopment, AND DEPLOYMENT}

The basic research work on sensory aids currently being carried out in the United States is scattered widely among university departments, research institutes, and business contractors each with his own strengths and weaknesses. Most of this work is pursued on an autonomous basis, and there are very few opportunities taken for organizations to complement one another in various roles.

Almost by definition, university technological research should serve some educational role. Other characteristics of university research are that it tends to be basic or fundamental in nature, direct competition with large industrial research programs is discouraged, a lack of fixed deadlines is desirable, and a rapid turnover in personnel may occur. Because of the subsidiary purposes of the research, the cost of doing research within a university tends to be somewhat lower than in the industrial counterpart. Given these characteristics, sensory-aids research is an attractive field for the technological school. The projects serve a humanitarian goal and are not in direct competition with the main thrust of industrial activity. Moreover, the solution of one or more of the many fundamental problems can be sought and in the process provide an excellent training for students who may be motivated to continue this work beyond their graduate training. Thus the potential of sensory-aids research to provide a sound training is an asset which should be fully utilized. However, these same characteristics also mean that the main output of these university projects is likely to be graduate theses containing some good ideas and theories that are nonetheless a long way from practical application.

A major part of the technological research support in visual impairment has gone to research institutes or foundations. These organizations maintain professional staffs and technical support facilities which are solely applied to research and development problems. Thus projects should be professionally and efficiently carried out through the development phases and according to a time schedule. Interdisciplinary problems can be efficiently attacked because experts in a wide range of fields are either on hand or can be easily assembled. Thus in addition to basic research, engineering development, testing, and some evaluation involving interdisciplinary skills can be expected from the research institute. However, manufacturing and marketing activities are usually not undertaken.

Commercial organizations who are or were at one time in the visual impairment field include the large concerns such as RCA [107] and Lockheed, and small contractors such as Mauch Labs [30] and Bionic Instruments [81]. Since, in terms of possible return on investment, the sensory-aids market for the blind is small, industrial research tends to be either supported by government contracts or company supported and justified in terms of corporate image ${ }^{5}$ rather than potential profit. Unlike the uni-

${ }^{5}$ This basis for justification typically relegates the activity to a low priority status. 
versity or the research institute, industrial organizations offer manufacturing capabilities as well as those of development and research. These organizations thus possess a considerable resource, the most valuable parts of which are largely untapped due to the severe economic restrictions that cloud the entire sensory-aids effort.

While all of these organizations, universities, research institutes, and industries have at one time been involved in sensory-aids research and development, seldom has there been any overt attempt in the U. S. to integrate their activities in such a way as to combine the strengths and avoid the weaknesses of each. A major barrier to more closely combined activities is the fragmentation of financial resources. This develops from the fact that the sensory-aids field falls within the bailiwick of at least five government agencies each with a responsibility for only a part of the total problem. Too often cooperation among programs funded by different agencies has been constrained by governmental procedures so that no effective interchange takes place. Perhaps more serious than this has been the lack of qualified staff within these agencies to stimulate, monitor, and evaluate technological research and development. Until recently, little or no engineering representation was present on study sections and little technical advice in proposal evaluation was taken, if at all. Also, the commonly accepted industrial practice of competitive bidding is still largely nonexistent. Thus, these agencies have lacked the ability to evaluate the scientific merits of technical proposals, to respond to the implications of new technological developments, and to effectively monitor and utilize the results from engineering grants and contracts. These aspects of the "blindness system" [1] in the United States have resulted in an overall sensory-aids research and development program that is small, poorly coordinated, inefficient, and contains a disproportionate and perhaps unnecessary duplication of effort.

Nevertheless, in spite of these difficulties, several devices have been developed to the point where they are presently in the field trial stage. In the event that these devices succeed in terms of proven utility, the blindness system will meet an even greater challenge; the comprehensive deployment of sensory aids for the blind. At the present time there appears to be little serious preparation being made to meet this challenge. However, an efficient flow pattern of effort from the inception of an idea to the ultimate deployment of a device must eventually be established. If this is to be done within the current structure of research and technology in this country, experience shows that either suffcient inducement must be offered to encourage the necessary participation of industry and the cooperation of other research centers, or a comprehensive research and development organization or National Center [19] must be set up, funded by government, and capable of carrying projects through the manufacture and deployment stage. It seems likely that, as more aids become available, the pressures to resolve the problems posed by manufacture and deployment needs will become more acute and that these proposals will eventually receive more serious attention.

\section{CONCLUSIONS}

In almost all past papers devoted to a review of sensory aids it has been customary to concentrate on the technical problems. To have continued in this tradition may have been more appropriate to an engineering journal, but a discussion of only the technical aspects would have revealed barely half of the problems. Successful sensory aids will undoubtedly not evolve without the application of concentrated technical and scientific effort, but if this effort is to be marshalled effectively, changes will have to occur both in our methods of assessing priorities on resources in the biomedical field and the manner in which these resources are deployed. In concise terms the lessons we must learn are the following.

First, the planning for this work requires a considerably better understanding of the basic demography and sociology of blindness.

Second, the problems of sensory-aid development do not lie exclusively in the technical arena but intersect many disciplines. Therefore, for their solution, these problems require well-integrated research programs and cannot be approached in a piecemeal fashion.

Third, evaluation plays a role of greater importance in the process of sensory-aid research and development than is customary in industrial $\mathrm{R}$ and $\mathrm{D}$. This fact must be acknowledged both in terms of appropriate funding procedures and in the provision of the necessary facilities within which these activities can be more closely integrated. The establishment of a National Center for Sensory Aid Research may ultimately be the most efficient way of meeting this need.

Fourth, the fragmentation of effort fostered by the policies of the funding agencies must be avoided. Greater efficiency could be achieved if national objectives were established and a coordinated program were developed.

Finally, solutions to the problems of providing prosthetic aids for the handicapped can and must be sought with greater resolve and in more diversified ways. Furthermore, meeting the needs of the handicapped must be recognized as a responsibility of us all, and it is in acknowledging this simple fact that the major challenge really lies.

\section{ACKNOWLEDGMENT}

The authors gratefully acknowledge the assistance of Dr. R. Mann on the topic of braille translation, Dr. F. Cooper on speech synthesis, and Dr. S. Genensky on the image intensifier. Mr. L. Clark, Dr. J. Flanagan, Dr. N. Guttman, Dr. R. Hoover, and Dr. D. Troxel generously provided thoughtful comments which were useful to us in composing the final draft.

\section{REFERENCES}

[1] D. A. Schon, "The blindness system," The Public Interest, pp. 25-38, Winter 1970.

[2] Statistics for 1966 on Blindness in the Model Reporting Area. Washington, D. C.: U. S. Govt. Printing Office, U. S. Dept. of Health, Education, and Welfare (HEW), Public Health Service, Nat. Institutes of Health, 1969.

[3] Estimated Statistics on Blindness and Visual Problems. New York: Nat. Soc. for the Prevention of Blindness Inc., 1966. 
[4] Selected Impairments. United States-July 1963-June 1965. Washington, D. C.: Nat. Center for Health Statistics, HEW, ser. 10, no. $48,1968$.

[5] H. Goldstein, The Demography and Causes of Blindness. Cambridge, Mass.: Harvard University Press (in press).

[6] - "The need for sensory devices market research," Res. Bull., New York: Amer. Foundation for the Blind, pp. 66-71, August 1963.

[7] P. G. Gray and J. E. Todd, Mobility and Reading Habits of the Blind (SS 386). London: Her Majesty's Stationary Office, 1968.

[8] T. J. Carroll, "Functional definitions of impaired vision: The implications for service programs: The philosophical viewpoint," Proc. 36th Conv. Amer. Assoc. of Workers for the Blind, Inc., 1962.

[9] M. D. Graham, "Functional definitions of impaired vision: The implications for service programs: The national viewpoint," Proc. 36th Conv. Amer. Assoc. of Workers for the Blind, Inc., 1962.

[10] R. E. Hoover, "Functional definitions of impaired vision: The implications for service programs: Visual efficiency as a criterion of service needs," Proc. 36th Conv. Amer. Assoc. of Workers for the Blind, Inc., 1962.

[11] B. J. Cratty, C. Peterson, J. Harris, and R. Schoner, "The development of perceptual-motor abilities in blind children and adolescents," The New Outlook for the Blind, April 1968.

[12] H. A. Witkin, J. Birnbaum, S. Lomonaco, S. Lehr, and J. L. Herman, "Cognitive patterning in congenitally totally blind children," Child Develop., vol. 39, pp. 767-786, September 1968.

[13] A. B. Scott, "The changing causes of blindness," Proc. West Coast Regional Conf. Res. Related to Blind and Severely Visually Impaired Children. New York: Amer. Foundation for the Blind, December 1965 , pp. $29-33$.

[14] R. A. Scott, "The social and cultural context of aging in American society," Proc. Res. Conf. Geriatric Blindness and Severe Visual Impairment, L. L. Clark, Ed. New York: Amer. Foundation for the Blind, 1968, pp. 29-36.

[15] E. Josephson, "Introduction," Proc. Res. Conf. on Geriatric Blindness and Severe Visual Impairment, L. L. Clark, Ed. New York: Amer. Foundation for the Blind, 1968, pp. 1-2.

[16] R. A. Scott, The Making of Blind Men. New York: Russell Sage Foundation, 1969.

[17] Blindness. Ann. publication, Amer. Assoc. for the Blind, Inc., Inc., 1511, K. Street, N. W., Washington, D. C.

[18] K. Trouern-Trend, "Blindness in the United States.Final summary report," Nat. Inst. of Neurological Disease and Blindness, Contract $\mathrm{PH}-43-67-1463$

[19] "Sensory aids for the blind," Rep. of 1967 Conf. Committee on Prosthetics Res. Develop., Nat. Res. Council Publ. 1691, Nat. Acad. Sci., Washington, D. C., 1968 ,

[20] C. Starr, "Social benefit versus technological risk," Science, vol. 165, pp. 1232-1238, 1969.

[21] J. C. Taenzer, "Visual word reading," IEEE Trans. Man-Machine Syst., vol. MMS-11, pp. 44-53, March 1970.

[22] J. C. Bliss, "Sensory aids for the blind," McGraw-Hill Yearbook of Science and Technology. New York: McGraw-Hill, 1966, pp. $357-360$.

[23] H. Freiberger and E. F. Murphy, "Reading machines for the blind," IRE Trans. Human Factors Electron., vol. HFE-2, pp. 8-19, March 1961

[24] P. W. Nye, "Reading aids for blind people-a survey of progress with the technological and human problems," Med. Elec. Biol. Eng., vol. 2, pp. 247-264, 1964.

[25] P. G. Shrager and C. Susskind, "Electronics and the blind," Advan. Electron Phys., vol. 20, pp. 261-301, 1964.

[26] E. Bennet, J. Degan, and J. Spiegel, Eds., Human Factors in Technology. New York: McGraw-Hill, 1963, ch. 17-25.

[27] P. A. Zahl, Ed., Blindness: Modern Approaches to the Unseen Environment. Princeton, N. J.: Princeton University Press, 1950. (Reprint, New York: Hafner, 1962.)

[28] E. E. Fournier d'Albe, "The Optophone: An instrument for reading by ear," Nature, vol. 105, pp. 295-296, 1920.

[29] J. L. Coffey, "The development and evaluation of the Battelle aural reading device," Proc. Int. Congr. Technol. and Blindness, L. L. Clark, Ed. New York: Amer. Foundation for the Blind, 1963 , vol. 1 , pp. $343-360$.

[30] G. C. Smith and H. A. Mauch, "Summary report on the development of a reading machine for the blind," Bull. Prosthetics Res., vol. BPR 10-12, Dept. of Medicine and Surgery, Veterans Admin., Washington, D. C., pp. 243-271, Fall 1969.
[31] C. G. Ritter, "Devices to aid the blind," Blindness: Modern Approaches to the Unseen Environment, P. A. Zahl, Ed. New York: Hafner, 1962, pp. 389-422.

[32] S. M. Genensky, "Some comments on a closed circuit T.V. system for the visually handicapped," Arch. Amer. Acad. of Optom., vol. 46, pp. 519-524, 1969.

[33] C. A. Weed, "Electronic image enlargement for the partially sighted (a description of apparatus and preliminary results)," Hartford Hosp. Bull., vol. 23, March 1968.

[34] A. M. Potts, D. Volk, and S. S. West, "A television reader," Amer. J. Ophthalmol., vol. 47, pp. 580-581, 1959.

[35] P. J. Davis, "Television reading aids," Mass. Comm. for the Blind, Boston, Mass.

[36] "Science for the Blind Inc.: A comprehensive report." Bala Cynwyd, Penn.: Science for the Blind Publ., 1968.

[37] "Final Report," submitted to Vocational Rehab. Admin., HEW, Contract SAV-1045-66 from the Sensory Aids Eval. Develop. Cent., M.I.T., Cambridge, Mass., 1967.

[38] J. C. Swail, "The development of instruments and aids for the blind at the National Research Council," Rehab. in Canada, vol. 14, pp. 7-10, 1966.

[39] T. D. Sterling, M. Lichstein, F. Scarpino, D. Stuebing, and W. Stuebing, "Professional computer work for the blind," Commun. Assoc. Comput. Machinery, vol. 7, pp. 228-231, 1964.

[40] B. F. Smith, "Pioneering with time-sharing computer service at Perkins School for the Blind," The Lantern, vol. 39, pp. 10-12, February 1970.

[41] Proc. Conf. New Processes for Braille Manufacture, Sensory Aids Eval. Develop. Cent., M.I.T., Louisville, Ky.: Amer. Printing House for the Blind, February 8-9, 1968.

[42] L. H. Goldish, "Braille in the United States: Its production, distribution, and use,"'S.M. thesis, M.I.T., Cambridge, Mass., January 1967, (available as an Int. Res. Inform. Rep. from Amer. Foundation for the Blind, 15 W. 16th St., New York, N. Y., 10011).

[43] E. E. Blanco, "Development of a punched-tape-to-braille 'direct' and continuous transducer," Soc. and Rehab. Services Dept. HEW. Eng. Projects Lab., Dept. of Mechan. Eng., M.I.T., Cambridge, Mass., Rep. DSR 70249-4, 1968

[44] J. K. Dupress, D. M. B. Baumann, and R. W. Mann, "Towards making braille as accessible as print," Eng. Projects Lab., M.I.T., Cambridge, Mass., Rep. DSR 70249-1, 1968.

[45] A. P. Grunwald, Argonne Nat. Lab., Argonne, Ill, personal communication.

[46] R. W. Mann, "A comprehensive, computer-based braille translating system," Proc. 7th Int. Conf. Med. and Biol. Eng. (Stockholm, Sweden), August 1967

[47] K. R. Ingham, "Braille, the language, its machine translation and display," IEEE Trans. Man-Machine Syst., vol. MMS-10, pp. 96-100, December 1969.

[48] E. K. Meacham, The East Indiaman. Boston, Mass. : Little Brown, 1968.

[49] V. H. Yngve, "Automatic machine translation: Potentialities for braille encoding," Proc. Int. Congr. Technol. and Blindness, L. L. Clark, Ed. New York: Amer. Foundation for the Blind, pp. 519-524, 1969.

[50] A. Schack, J. Schack, R. Haynes, and J. Siems, "Computer translation: Grade II braille from print," Amer. Printing House for the Blind, Louisville, Ky, June 1969.

[51] J. K. Millen, "Dotsys II-choice of COBOL for braille translation," Mitre Corp., Bedford, Mass., Rep. MTR-1743, December 1969

[52] J. C. Bliss, "A relatively high-resolution reading aid for the blind," IEEE Trans. Man-Machine Syst., vol. MMS-10, pp. 1-9, March 1969.

[53] J. S. Brugler, J. D. Meindl, J. D. Plummer, P. J. Salsbury, and W. T. Young, "Integrated electronics for a reading aid for the blind," IEEE J. Solid-State Circuits, vol. SC-4, pp. 304-311, December 1969.

[54] P. J. Salsbury and J. D. Meindl, "A monolithic image sensor for a reading aid for the blind," Proc. IEEE, vol. 58, pp. 1302-1314, September 1970

[55] J. C. Bliss and K. W. Gardiner, "An optical-to-tactile image converter," Proc. Int. Conf. on Sensory Devices for the Blind, R. Dufton, Ed. London: St. Dunstan's, 1967, pp. 299-308.

[56] J. C. Bliss, "Optical to tactile image conversion for the blind," Stanford University, Stanford, Calif., Final Rep. May 1967-June 1969. 
[57] M. P. Beddoes, "An inexpensive reading instrument with a sound output for the blind," IEEE Trans. Bio-Med. Eng., vol. BME-15, pp. 70-79, April 1968.

[58] M. P. Beddoes and C. Y. Suen, "Evaluation and a method of presentation of the sound output from the Lexiphone-a reading machine for the blind," IEEE Trans. to be published in Bio-Med. Eng., vol. BME-18, April 1971.

[59] M. F. Metfessel, "Experimental studies of human factors in perception and learning of spelled speech," Proc. Int. Congr. on Technol. and Blindness, L. L. Clark, Ed. New York: Amer. Foundation for the Blind, 1963, vol. 1, pp. 305-308.

[60] L. N. Kanal, Ed., Pattern Recognition: Proc. IEEE Workshop on Pattern Recognition Held at Dorado, Puerto Rico. Washington, D. C.: Thompson Book Co., 1968.

[61] G. C. Smith and H. A. Mauch, "The development of a reading machine for the blind: Summary report," Bull. Prosthetics Res., vol. BPR 10-6, Dept. of Med. and Surgery, Veterans Admin., Washington, D. C., pp. 98-124, Fall 1966.

[62] J. C. Bliss, J. Munson, R. Savoie, and R. Shepard, "Simulation of a reading system for the blind," Final Rep., Nat. Eye Inst., Stanford Res. Inst., Grant 5 R01 EY00450-02, 1970

[63] S. J. Mason, F. F. Lee, and D. E. Troxel, "Reading machine for the blind," Quart. Prog. Rep. No. 89 Res. Lab. of Electronics, M.I.T. Cambridge, Mass., pp. 245-248, 1968.

[64] D. E. Troxel and K. R. Ingham, "Page reader for a reading machine for the blind," Quart. Prog. Rep. No. 94 Res. Lab. of Electronics, M.I.T., Cambridge, Mass., pp. 233-248, 1969.

[65] S. J. Mason and J. K. Clemens, "Character recognition in an experimental reading machine for the blind," Recognizing Patterns, P. A. Kolers and M. Eden, Eds. Cambridge, Mass.: M.I.T. Press, 1968, pp. 156-167.

[66] K. R. Ingham, "Spelled speech as an output for computers and reading machines for the blind," IEEE Trans. Human Factors Eng., vol. HFE-8, pp. 175-181, September 1967

[67] F. F. Lee, "Reading machine: From text to speech," IEEE Trans. Audio Electroacoust., vol. AU-17, pp. 275-282, December 1969.

[68] F. S. Cooper, "Review and summary," Proc. of the Int. Congr. on Technol. and Blindness, L. L. Clark, Ed. New York: Amer. Foundation for the Blind, 1963, vol. 1, pp. 381-392.

[69] F. S. Cooper, J. H. Gaitenby, I. G. Mattingly, and N. Umeda, "Reading aids for the blind: A special case of machine-to-man communication," IEEE Trans. Audio Electroacoust., vol. AU-17, pp. 266-270, December 1969.

[70] E. L. Thorndike and I. Lorge, Teacher's Word Book of 30,000 Words. New York: Teacher's College, Columbia Univ., 1944.

[71] I. G. Mattingly. "Experimental methods for speech synthesis by rule," IEEE Trans. Audio Electroacoust., vol. AU-16, pp. 198-202, June 1968.

[72] A. M. Liberman, F. Ingemann, L. Lisker, P. Delattre, and F. S. Cooper, "Minimal rules for synthesizing speech," J. Acoust. Soc. Amer., vol. 31, pp. 1490-1499, 1959.

[73] J. A. Leonard, "Mobility and the blind: A survey," Med. Elec. Biol. Eng., vol. 1, pp. 465-481, 1963.

[74] M. B. Clowes, "Summary statement: Some remarks on mobility theory," Proc. Rotterdam Mobility Conf., New York: Amer. Foundation for the Blind, 1962, pp. 169-170.

[75] A. Krigman, "A mathematical model of blind mobility," Projects Lab., M.I.T., Cambridge, Mass., Rep. 70249-2, April 1967.

[76] Proc. Conf. Eval. Mobility Aids for the Blind, Airlie House, June 1970. Washington D. C.: Nat. Acad. Eng., (in press).

[77] R. W. Mann, "The evaluation and simulation of mobility aids for the blind," Res. Bull., New York: Amer. Foundation for the Blind, pp. 93-98, October 1965.

[78] J. A. Leonard and R. C. Newman, "Three types of 'maps' for blind travel," Ergonomics, vol. 13, pp. 165-179, March 1970.

[79] D. Liddle, "Cane travel: Techniques and difficulties," Res. Bull., New York: Amer. Foundation for the Blind, pp. 1-62, October 1965.

[80] T. A. Benham, "The Bionic instruments travel aid," Proc. Int. Conf. on Sensory Devices for the Blind, R. Dufton, Ed. London: St. Dunstan's, 1967, pp. 255-274.

[81] J. M. Benjamin, "A review of the Veterans Administration blind guidance device project," Bull. Prosthetics Res., vol. BPR 10-9, pp. 63-90, 1968.

[82] R. E. Hoover, "Foot travel without sight: Foot travel at Valley
Forge," Outlook for the Blind, vol. 40, pp. 246-251, 1946.

[83] L. Kay, "Active energy radiating systems; ultrasonic guidance for the blind," Proc. Int. Congr. on Tech. and Blindness, L. L. Clark, Ed. New York: Amer. Foundation for the Blind, 1963, vol. 1, pp. $137-156$

[84] L. Kay, "Ultrasonic spectacles for the blind," Proc. Int. Conf. on Sensory Devices for the Blind, R. Dufton, Ed. London: St. Dunstan's, 1967, pp. 275-292.

[85] J. Juurmaa, "On the accuracy of obstacle detection by the blindpt. 2," The New Outlook for the Blind, vol. JR 64, pp. 104-118, April 1970.

[86] J. A. Leonard and A. Carpenter, "Trial of an acoustic blind aid," Res. Bull., New York: Amer. Foundation for the Blind, pp. 70-119, January 1964.

[87] C. E. Rice, "Quantitative measures of unaided echo detection in the blind: Auditory echo localization," Proc. Int. Conf. on Sensory Devices for the Blind, R. Dufton, Ed. London: St. Dunstan's, 1967, pp. 89-102.

[88] J. P. Wilson, "Obstacle detection using ambient or self-generated noise," Nature, vol. 211, p. 218, July 1966.

[89] T. V. Cranmer, "Evaluation of the Ultra electronics sonic mobility aid in Kentucky," Proc. Int. Conf. on Sensory Devices for the Blind, R. Dufton, Ed. London: St. Dunstan's, 1967, pp. 143-152.

[90] R. J. Wycherley and B. H. Nicklin, "The heart rate of blind and sighted pedestrians on a town route," Ergonomics, vol. 13, pp. 181-192, March 1970.

[91] L. Russell, "Travel path sounder-further results," Proc. Int. Conf. on Sensory Devices for the Blind, R. Dufton, Ed. London: St. Dunstan's, 1967, pp. 293-297.

[92] - Pathsounder Instructor's Handbook. Cambridge, Mass.: Sensory Aids Eval. Develop. Cent., M.I.T., January 1969.

[93] O. Foerster, "Beitrage zur Pathophysiologie der Sehbahn und der Sehsphare," J. Psychol. Neurol., Lpz, vol. 39, pp. 463-485, 1929.

[94] F. Krause and H. Schum, Neue deutsche Chirurgie, H. Kuttner, Ed. Stuttgart: Enke, vol. 49a, 1931, pp. 482-486.

[95] G. S. Brindley and W. S. Lewin, "The sensations produced by electrical stimulation of the visual cortex," J. Physiol., vol. 196, pp. 479-493, 1968.

[96] H. Schimmel and H. G. Vaughan, "Feasibility of visual electrocortical prosthesis: Pt. II design studies," Visual Prosthesis the Interdisciplinary Dialogue, E. Bering, S. Pollack, H. Vaughan, and T. Sterling, Eds. New York: Academic Press (in press).

[97] W. Starkiewicz and T. Kuliszewski, "The 80-channel Elektroftalm," Proc. Int. Congr. on Tech. and Blindness, L. L. Clark, Ed. New York: Amer. Foundation for the Blind, 1963, vol. 1, pp. 157-166.

[98] - "Progress report on the Elektroftalm mobility aid," Proc. Rotterdam Mobility Res. Conf., L. L. Clark, Ed. New York: Amer. Foundation for the Blind, 1962, pp. 27-38.

[99]. J. C. Bliss and K. W. Gardiner, "A mobility aid for the blind to supplement the cane," Final Rep., Stanford Res. Inst., Project 4213, 1966.

[100] P. Bach-y-Rita, C. C. Collins, F. A. Saunders, B. White, and L. Scadden, "Visual substitution by tactile image projection," Nature vol. 221, pp. 963-964, 1969.

[101] R. Dufton, Ed., Proc. Int. Conf. on Sensory Devices for the Blind, Rep. Practical Trials of the Sonic Torch. London: St. Dunstan's, 1967, pp. 105-211.

[102] J. W. Linsner, Ed., Proc. Conf. Mobility Rehab. Specialists. New York: Amer. Foundation for the Blind, 1962.

[103] L. L. Clark, Ed., Proc. Rotterdam Mobility Res. Conf. New York: Amer. Foundation for the Blind, 1965.

[104] J. A. Leonard and R. J. Wycherley, "Towards the measurement of performance of travel skill," Proc. Conf. Mobility Trainers and Technologists (M.I.T., December 1967). New York: Amer. Foundation for the Blind, pp. 27-45.

[105] J. L. Coffey and R. R. McFarland, "The evaluation and standardization of selection and training procedures for the Battelle aural reading device." Final Rep., Veterans Admin., Battelle Memorial Inst., Columbus, Ohio, Contract V1005 M-1961, June 1963.

[106] B. H. Deatherage, "The evaluation of the Haverford-Bionic instruments obstacle detector," Proc. Rotterdam Mobility Res. Conf., L. L. Clark, Ed. New York: Amer. Foundation for the Blind, 1965 , pp. 201-233.

[107] Final Rep. Develop. Letter Recognition Reading Machine for the Blind. R.C.A. Lab., March 31, 1948. 


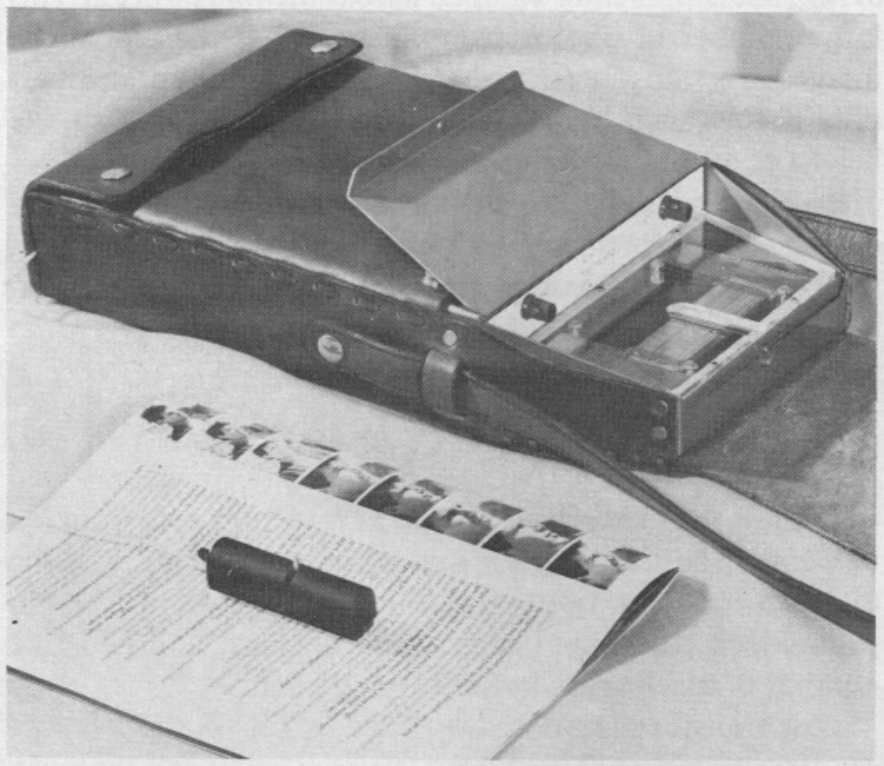

Fig. 3. The Optacon: a direct-translation reading aid which presents on a 24 by 6 matrix of stimulators, a tactile facsimile image of printed characters scanned by the optical probe. 


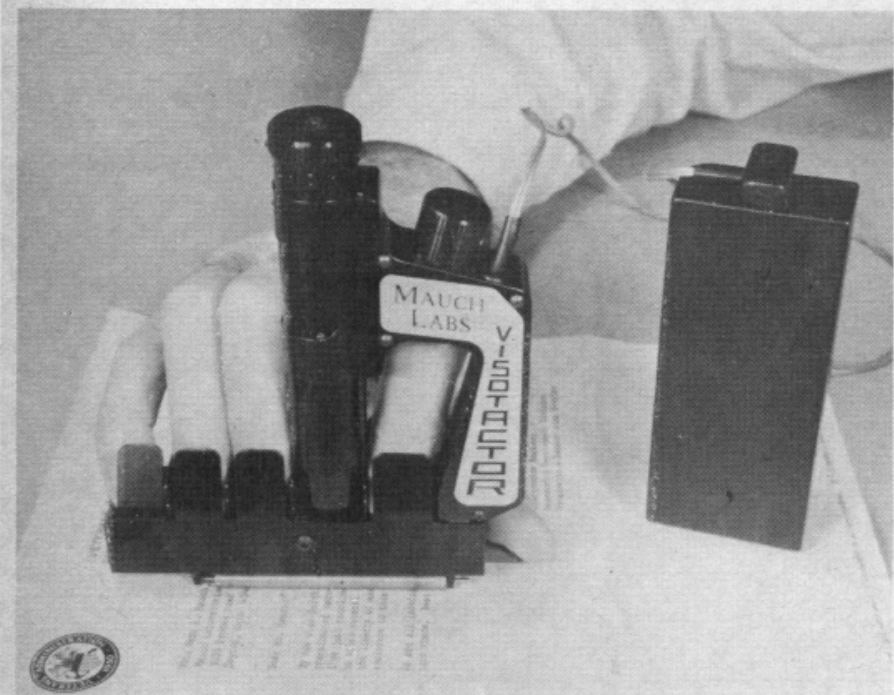

Fig. 4. The Visotactor: a direct-translation reading aid which utilizes 8 stimulators ( 2 stimulators per finger tip) that are built into the optical probe.

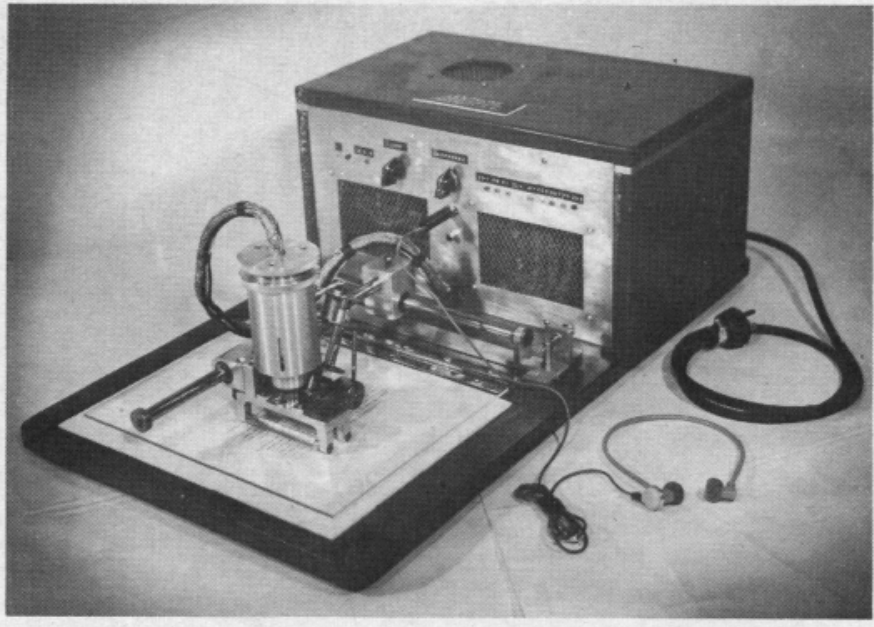

Fig. 5. The Lexiphone: a direct-translation reading aid which generates a complex nonspeech audio output that the reader must be trained to understand. 


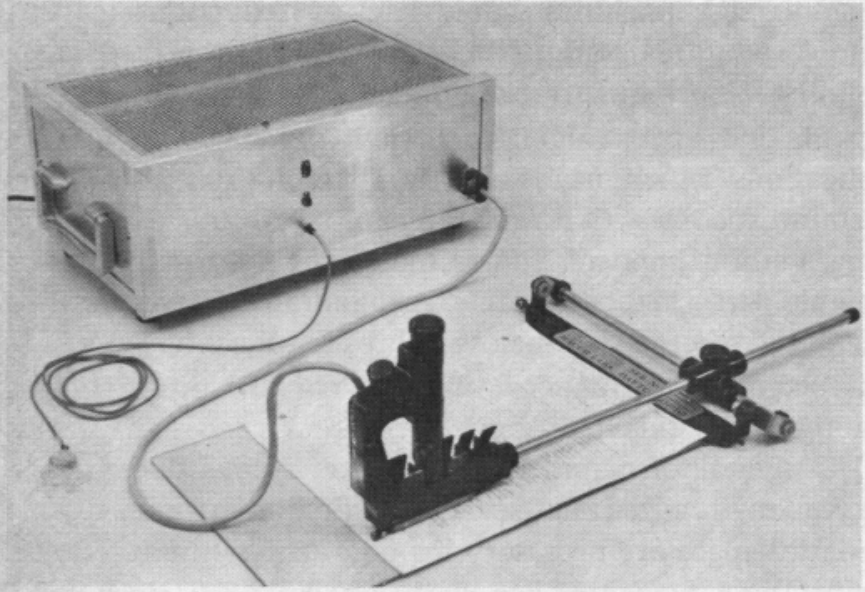

Fig. 7. The Cognodictor: a recognition reading machine providing a spelled speech output. Input is provided by a Digitactor probe fitted with the photocell array depicted in Fig. 8. 


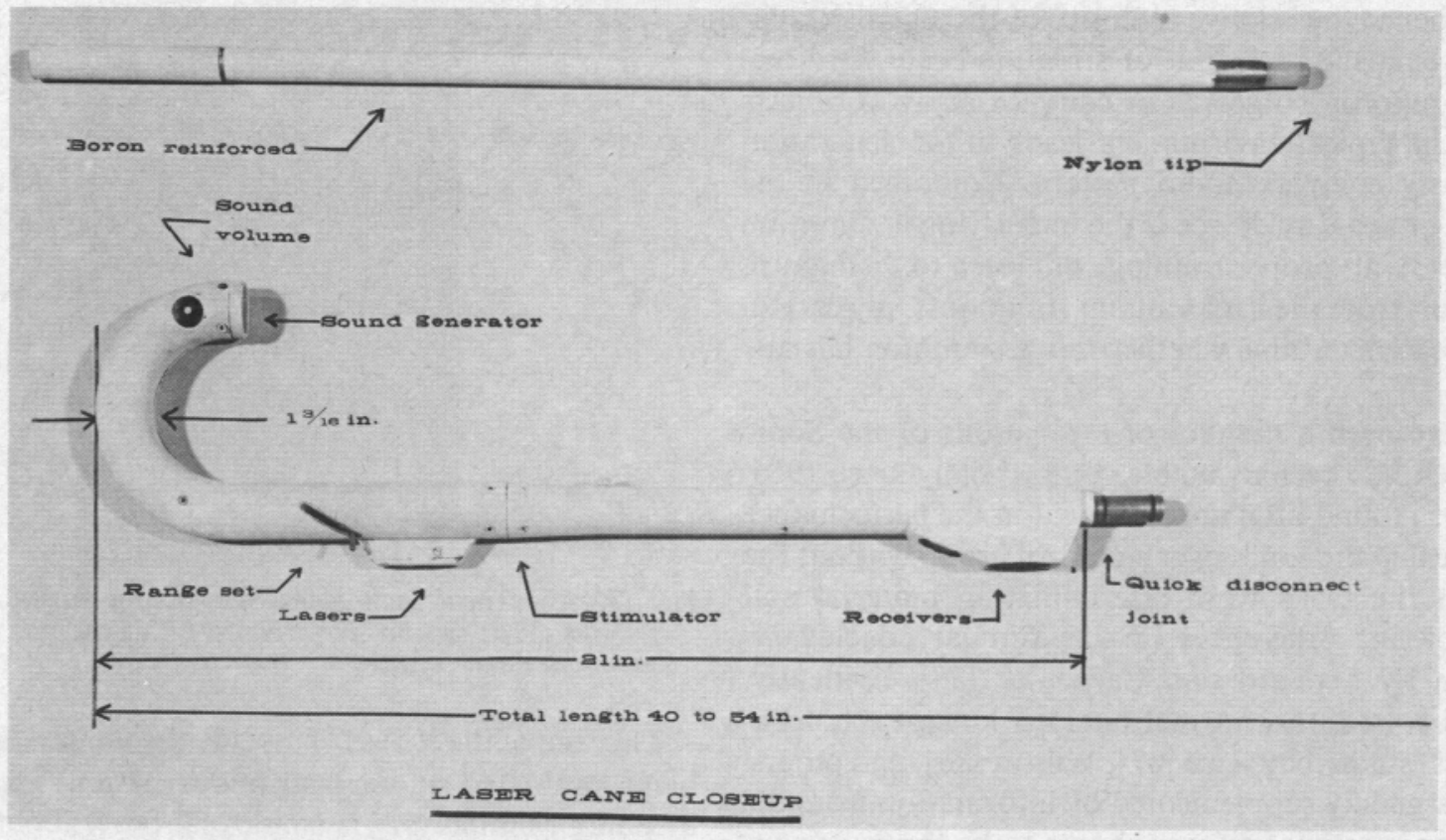

Fig. 11. The Bionic cane seen in detail. 


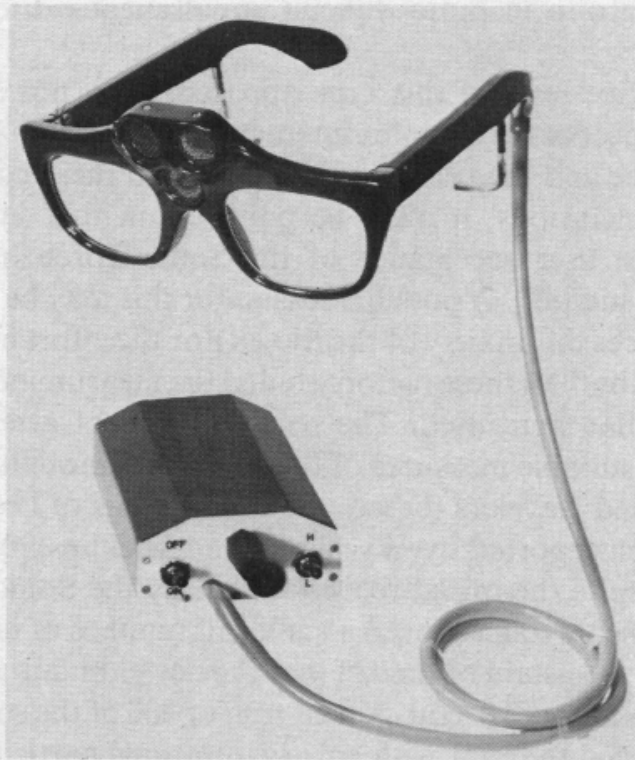

Fig. 12. The Ultrasonic Spectacles designed by Kay. Transmitters and receivers are located at the bridge of the nose. Batteries are located in a vest pocket carrying case. 
REMOTE AUDIO JACK

NECKLOOP SPEAKERS

\section{CLASP}

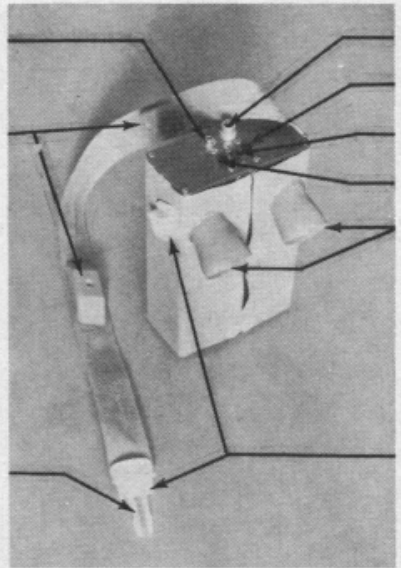

CHARGING JACK

ON-OFF SWITCH

RAMP SWITCH

LOUDNESS SWITCH

SONAR HORNS

CLASP RECEPTACLE

Fig. 13. The Travel Pathsounder designed by Russell. Transmitter, receiver, electronics, and power source are all enclosed within a single case worn about the neck. 


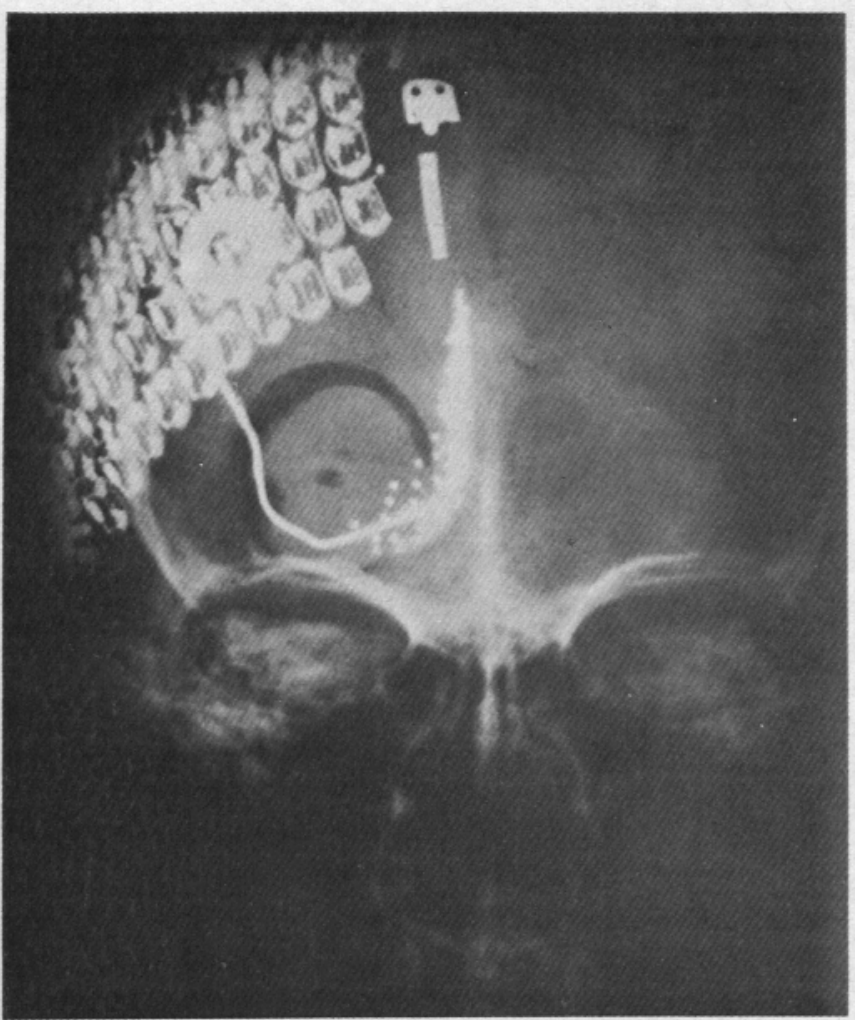

Fig. 14. An X-ray photograph of the head of the female subject employed in Brindley and Lewin's experiments. The receivers can be seen in the top left hand corner of the figure. The electrodes are located beneath the skull. (From J. Physiol., vol. 196, 1968, with permission.) 


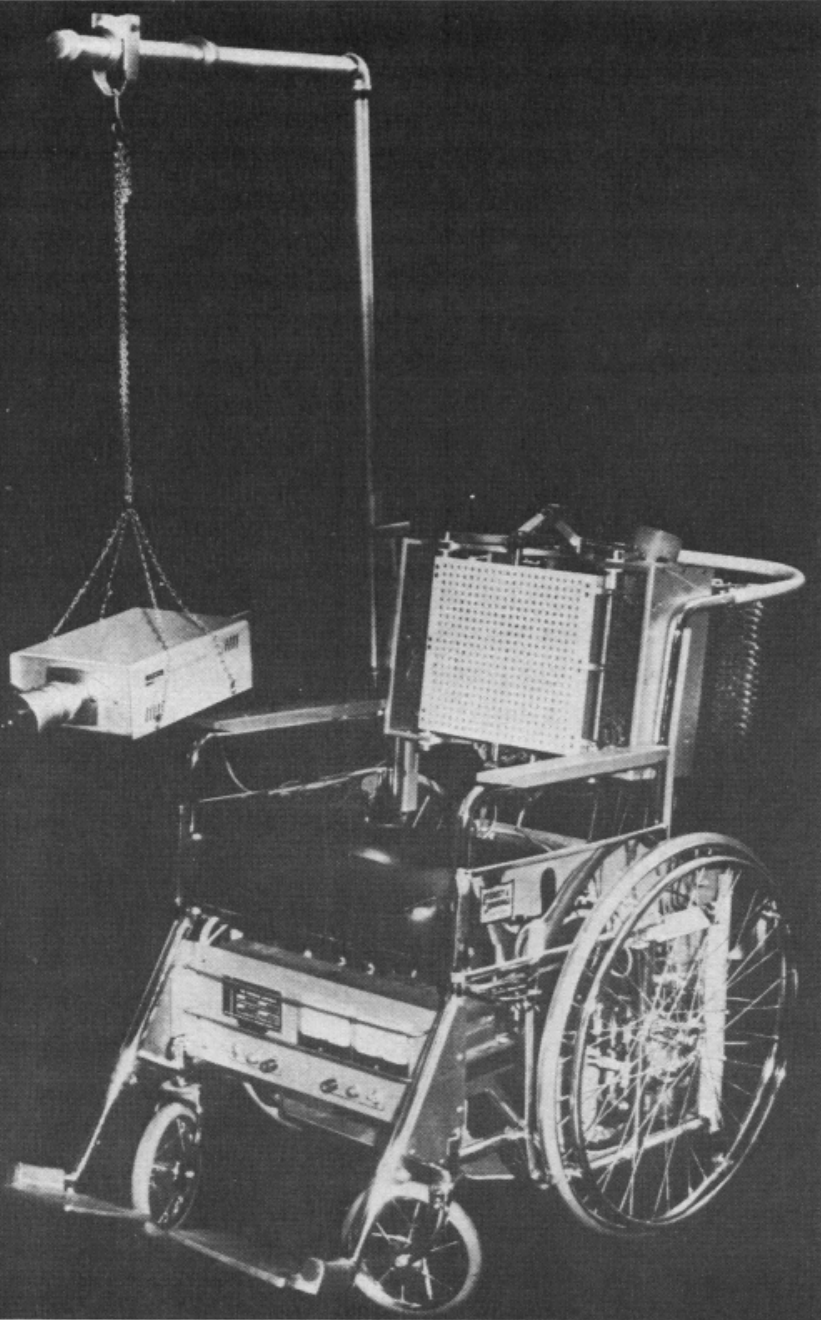

Fig. 15. The visual substitution system of Bach-y-Rita et al. [100]. A television camera is supported by an overhead member. The 20 -by-20 array of tactile stimulators is located in the chair back. 